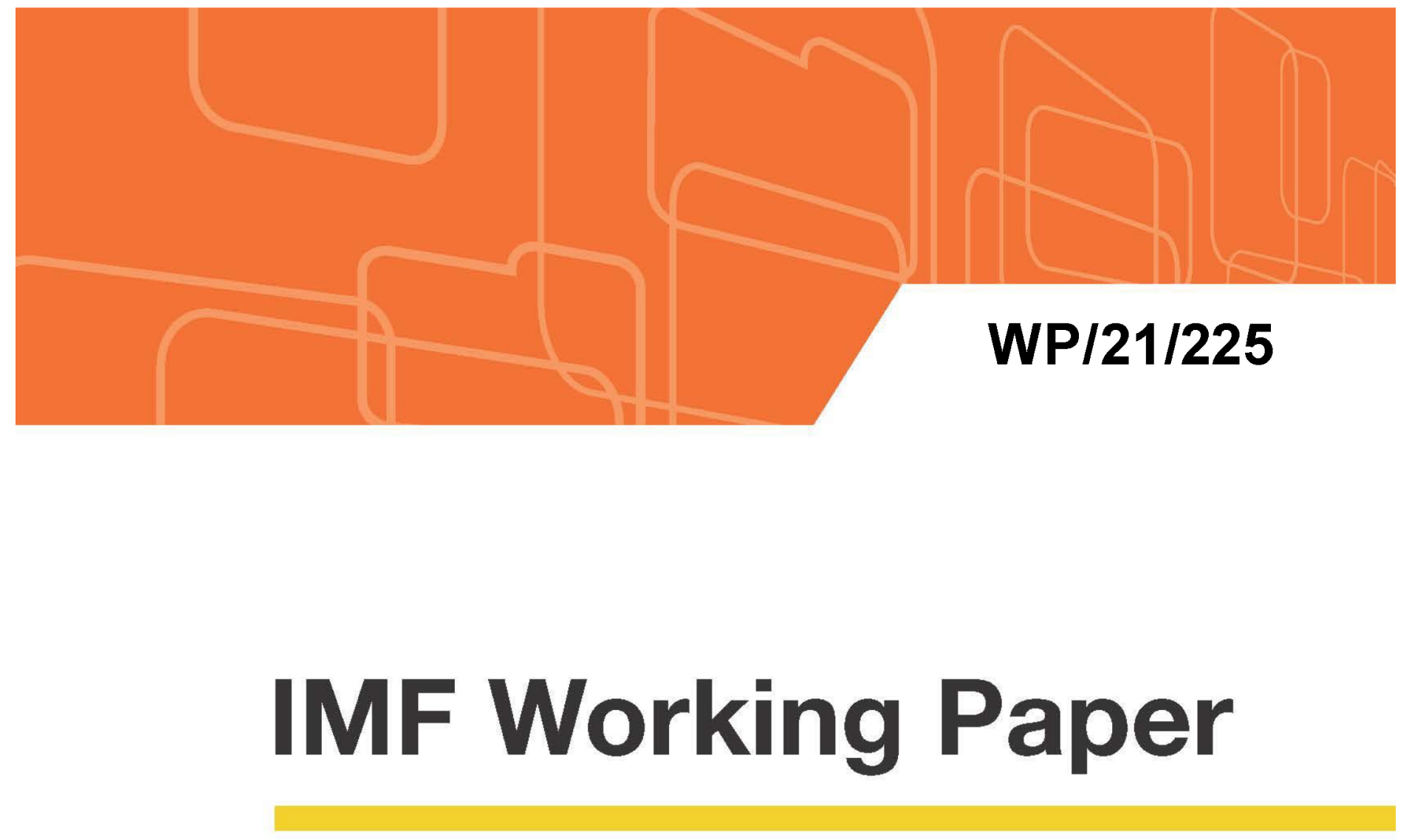

\title{
Tracking Trade from Space: An Application to Pacific Island Countries
}

by Serkan Arslanalp, Robin Koepke, and Jasper Verschuur

IMF Working Papers describe research in progress by the author(s) and are published to elicit comments and to encourage debate. The views expressed in IMF Working Papers are those of the author(s) and do not necessarily represent the views of the IMF, its Executive Board, or IMF management.

$$
\text { I N T E R N A T I O N A L M O N E T A R Y FU N D }
$$




\title{
IMF Working Paper
}

Asia and Pacific Department and Statistics Department

\section{Tracking Trade from Space: An Application to Pacific Island Countries \\ Prepared by Serkan Arslanalp, Robin Koepke, and Jasper Verschuur ${ }^{1}$}

Authorized for distribution by Carlos Sánchez-Muñoz and Todd Schneider

August 2021

\begin{abstract}
IMF Working Papers describe research in progress by the author(s) and are published to elicit comments and to encourage debate. The views expressed in IMF Working Papers are those of the author(s) and do not necessarily represent the views of the IMF, its Executive Board, or IMF management.
\end{abstract}

\begin{abstract}
This paper proposes an easy-to-follow approach to track merchandise trade using vessel data and applies it to Pacific island countries. Pacific islands rely heavily on imports and maritime transport for trade. They are also highly vulnerable to climate change and natural disasters that pose risks to ports and supply chains. Using satellite-based vessel tracking data from the UN Global Platform, we construct daily indicators of port and trade activity for Pacific island countries. The algorithm significantly advances estimation techniques of previous studies, particularly by employing ways to overcome challenges with the estimation of cargo payloads, using detailed information on shipping liner schedules to validate port calls, and applying country-specific information to define port boundaries. The approach can complement and help fill gaps in official data, provide early warning signs of turning points in economic activity, and assist policymakers and international organizations to monitor and provide timely responses to shocks (e.g., COVID-19).

JEL Classification Numbers: C53, C55, F17

Keywords: Big Data, Climate Change, Trade, Asia and Pacific, Global Supply Chains

E-Mail Address: sarslanalp@,imf.org; rkoepke@,imf.org; jasper.verschuur@,keble.ox.ac.uk
\end{abstract}

\footnotetext{
${ }^{1}$ Jasper Verschuur is a PhD student in Geography and the Environment at the Environment Change Institute of Oxford University. The authors are grateful to Gian Maria Milesi-Ferretti, Gabriel Quirós-Romero, Andrea Richter Hume for very helpful suggestions and discussions, Markie Muryawan and Ronald Jansen for support with the UN Global Data Platform, and Diego Cerdeiro, Gabriela Cugat, Kenneth Egesa, Tatiana Goriainova, Talavai Iona, Andras Komaromi, Nilima Lal, Yang Liu, Marco Marini, Silvia Matei, Glenn McKinlay, Ayoub Mharzi, Markie Muryawan, Rommel Rabanal, Daniel Rodriguez, Alberto Sanchez, Charlotte Sandoz, Alessandra Sozzi, Vincent Stamer, Stellios Stratidakis, Mark Sturton, Jim Tebrake, Patrizia Tumbarello, Jarkko Turunen, Jiaxiong Yao for very helpful comments. Redley Pinkney and Tatiana Carandang provided excellent administrative and editorial assistance.
} 
II. STYLIZED FACTS ABOUT PACIFIC ISLANDS

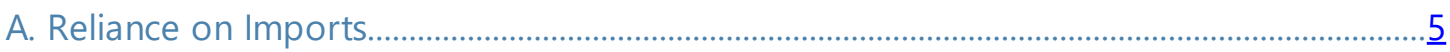

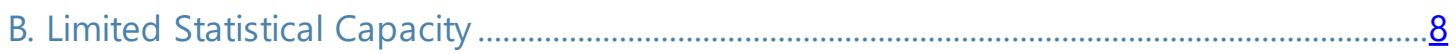

C. Vulnerability to Climate Change and Natural Disasters...............................................................

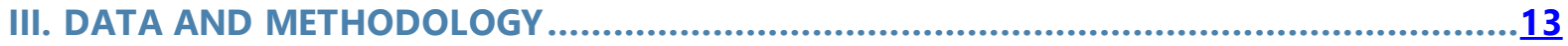

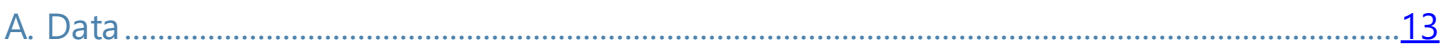

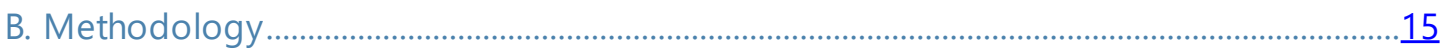

IV. TRACKING TRADE IN THE PACIFIC DURING THE COVID-19 PANDEMIC ..................

A. Supply Disruptions in the Early Stage

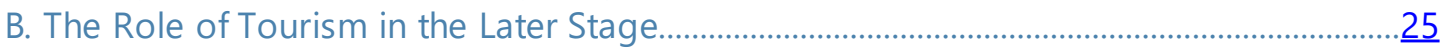

V. CONCLUSIONS AND POSSIBLE EXTENSIONS $\ldots \ldots \ldots \ldots \ldots \ldots \ldots \ldots \ldots \ldots \ldots \ldots \ldots \ldots \ldots \ldots \ldots \ldots \ldots \ldots \ldots \ldots \ldots \ldots$

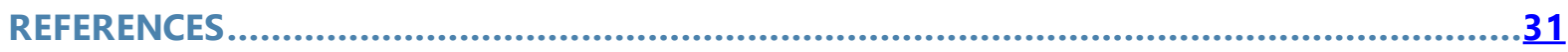

TABLE

1. Pacific Island Countries: Port Calls by Type of Ship During 2019-20................................18

FIGURES

1A. Pacific Island Countries: Merchandise Imports and Exports, 2019 ....................................

1B. Pacific Island Countries: Merchandise Imports by Sea ........................................................

2. Pacific Islands and Other Small States: Liner Shipping Connectivity Index.....................

3A. Correlation of GDP and Merchandise Imports ........................................................................

3B. Pacific Island Countries: Timeliness of Merchandise Trade Data .......................................

4. Pacific Island Countries: Climate Risk Index ...........................................................................10

5A. Selected Pacific Islands: Port Boundaries................................................................................17

5B. Pacific Islands: Major International Ports ...........................................................................18

6. The Impact of COVID-19 Pandemic on Regional Trade in the Pacific..............................24

7A. Pacific Island Countries: Import Value, 2020........................................................................

7B Pacific Island Countries: Import Volume, 2020 .......................................................................... 25

8. Pacific Island Countries: International Tourism Receipts........................................................ 26

9. Selected Pacific Island Countries: Visitor Arrivals........................................................................

10. Pacific Islands: Tourism Estimates for 2020................................................................................26

11. Pacific Island Countries: Merchandise Imports, 2020 (Percent Change Compared to 2019; Year to Date; Value in USD)............................................................................................ 27

12. Merchandise Imports, 2020 (Percent Change from 2019) …............................................. 27 
13. Pacific Island Countries: Merchandice Imports, 2020 (Percent Change Compared to a Year Ago; in Volume Terms).

\section{BOXES}

1. Vulnerability of Pacific Island Ports to Climate Change and Natural Disasters ...........12

2. Shipping Lines Serving the Pacific Islands.................................................................................

3. Country Validations-Quality Assurance of Satellite AIS Indicators......................................

4. Comparison with Official Trade Data ..................................................................................................

ANNEXES

AnNeX TABLE I. CENTRAL LOCATION OF PACIFIC ISLAND PORTS..........................................................

ANNEX CHARTS I. PACIFIC ISLAND COUNTRIES: PORT CALLS, ..............................................................

AnNeX ChaRTS II. PACIFIC ISLANd COUNTRIES: IMPORT VOLUME ........................................................... 


\section{INTRODUCTION}

Over the last decade, a growing number of studies have begun to use satellite data for economic analysis. Donaldson and Storeygard (2016) note that a revolution has taken place in remote sensors and related fields such as computer science, engineering, and geographydramatically changing the way economists can learn by watching the planet from above. This paper provides an application of this approach for merchandise trade in the Pacific.

Pacific islands are small open economies vulnerable to climate change and natural disasters. ${ }^{2}$ They consist of remote and dispersed islands served by a few container lines ("sea locked"), as indicated by their low liner connectivity index and high transportation costs (Riku, 2021; UNCTAD, 2014 and 2020). ${ }^{3}$ As such, they have a few large trading partners (Australia, China, Japan, New Zealand, United States) that make them vulnerable to supply shocks in those countries. As their economies are not diversified, they are dependent on imports of manufactured goods for both consumption and investment. Some are also reliant on tourism, while others receive almost no tourism. In general, they have limited statistical capacity that hinders the timely production of essential macroeconomic data. As a result, one of the few pieces of hard data to track their economies is customs data on merchandise trade.

Using satellite-based vessel tracking data from the UN Global Platform, we construct daily indicators of port and trade activity for Pacific islands, which can help fill gaps in official data, provide early warning signs of turning points in economic activity, and track the impact of natural disasters and other shocks in real time. In turn, this can assist policymakers and international organizations in providing timely responses to such shocks.

Our daily indicators of port and trade activity can be useful during normal times - when policymakers are trying to formulate budgets or adjust policies in the absence of timely data - as well as extreme events, such as natural disasters or a pandemic. The approach can be replicated and extended by others using data from the UN Global Platform.

Apart from estimating trade at a country/port level, our approach also allows us to monitor changes in the Pacific maritime network, which is served by two major hubs: Guam in the North Pacific and Fiji in the South Pacific. In that context, we highlight the importance of the resilience of the whole network, not just each country's port. Countries can climate-proof

\footnotetext{
${ }^{2}$ Throughout the paper, we use Pa cific island countries, Pacific islands, and small island states in the Pacific, interchangeably. The group includes (with country codes in parenthesis): Fiji(FJI), Kiriba ti(KIR), Marshall Islands (MHL), Federated States of Micronesia (FSM), Na uru (NRU), Pa lau (PLW), Samoa (WSM), Solomon Islands (SLB), Tonga (TON), Tuvalu (TUV), and Vanuatu (VUT). The IMF defines small sta tes a s those with a population of 1.5 million people or less. Sma ll sta tes represent a bout a quarter of theIMF's membership.

${ }^{3}$ Several factors combine to make shipping services to Pacific island countries rela tively expensive. These include long dista nces between ports, small and dispersed populations, low tra de volumes, imbalance in tra de with exports usually far outweighed by imports, and varying quality of port facilities (ADB, 2007).
} 
their ports, but if others in the network do not make the same investments, they could still be affected by port disruptions elsewhere in an interconnected trade system.

The paper contributes to the literature in several ways. First, to the best of our knowledge, this is the most comprehensive methodology for overcoming challenges with vessels' Automatic Identification System (AIS) data to estimate trade. It includes the use of (i) appropriate filtering, backpropagating, historical averaging techniques to overcome possible measurement errors with AIS data; (ii) vessel-specific information to avoid estimating trade volumes linearly with draft changes; and (iii) use of domain expertise, including country/port specific information and liner shipping schedules, to improve the accuracy of estimates. Second, the approach outlined in this paper does not require access to commercial data sources. Third, the results can be replicated transparently by others with access to the UN Global Platform as we make the underlying algorithm available for research purposes. ${ }^{4}$

Another key contribution of this paper is that it provides a way to derive high-frequency indicators of trade and economic activity in an otherwise data scarce environment. Although such indicators are often available at the global level (Cerdeiro et al., 2020; J.P. Morgan, 2020; Verschuur, Koks, and Hall, 2020; Stamer 2021) or derived for larger economies (Arslanalp, Marini, and Tumbarello, 2019; Noyvirt, 2019), their use for small island states were not explored to a full extent before, given issues of data availability, susceptibility to outliers, and high internal variability of time series. This is also addressed in the paper.

The rest of the paper is organized as follows. Section II provides stylized facts about Pacific islands to motivate the paper. Section III describes the data sources and methodology used to construct the trade estimates. Section IV provides an application of our approach during the COVID-19 pandemic in 2020. The final section examines some of the policy implications and possible extensions of our approach.

\section{Stylized FaCts About PACIFIC ISLANDS}

This section presents three stylized facts about small island states in the Pacific, particularly their (i) reliance on imports, particularly by sea; (ii) limited statistical capacity; and (iii) vulnerability to climate change and natural disasters.

\section{A. Reliance on Imports}

Many essential goods and virtually all manufactured goods in Pacific islands are importedmainly by sea. Pacific island countries are heavily reliant on imports due to their small undiversified economies, similar to other small island states (Briguglio, 1995). On average, imports of goods make up about 60 percent of GDP for Pacific islands (Figure 1A). In contrast, exports of goods (excluding re-exports) are less than 10 percent of GDP for all

\footnotetext{
${ }^{4}$ The algorithm and defined portboundaries used in this paper are available from the authors upon request.
} 
Pacific islands, except for Fiji (sugar), Nauru (phosphate), and Solomon Islands (timber). ${ }^{5}$ Given that imports dominate exports for Pacific Islands, import traffic (as opposed to export traffic) typically determines the vessel traffic at Pacific island ports (ADB, 2020). Overall, 80-100 percent of all imports (by value) arrive through seaports (Figure 1B).
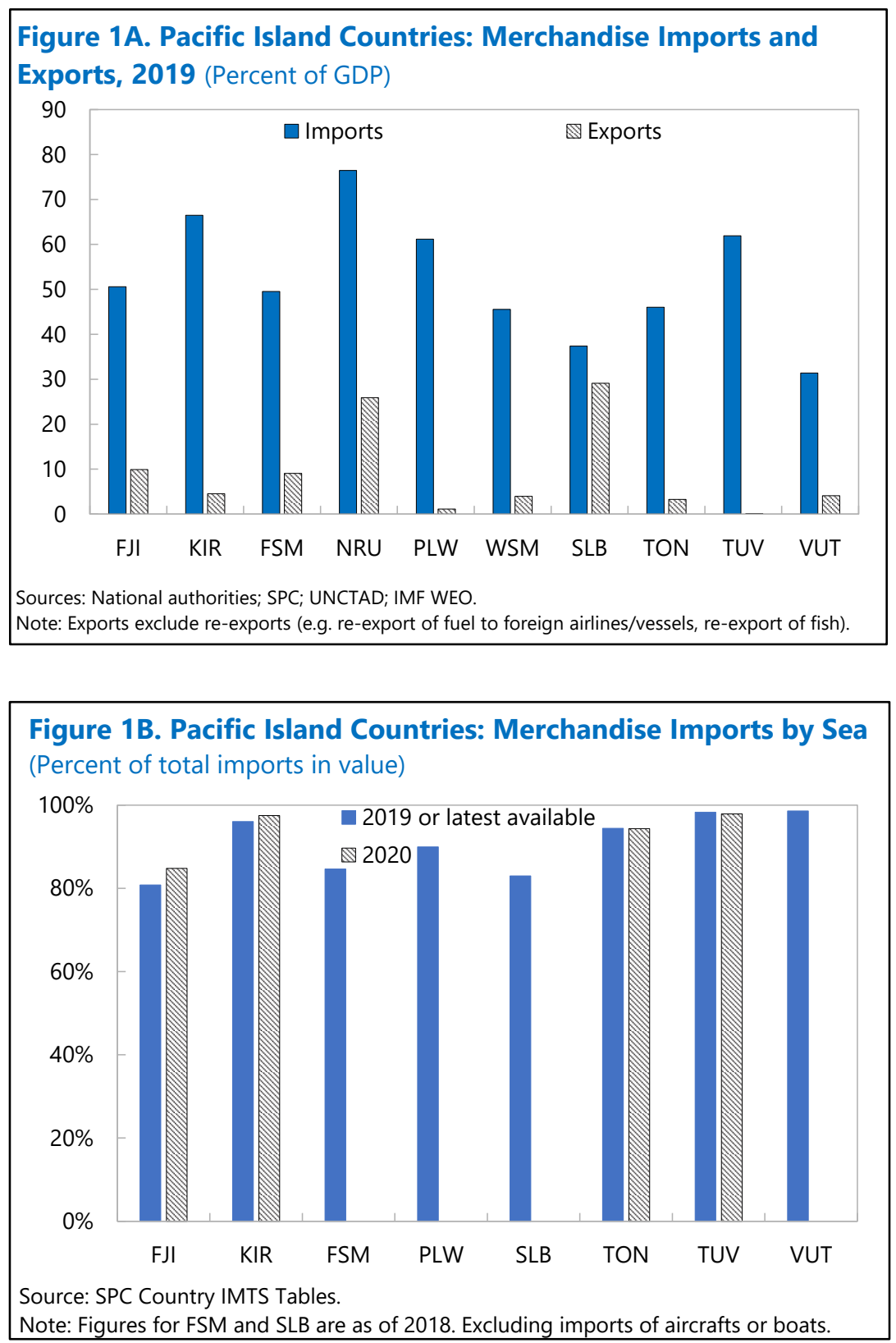

\footnotetext{
${ }^{5}$ The region has large resources in fishing. However, fishing a ctivity is predominantly done by foreign fishing vessels which pay a fishing license fee for theright to fish in the exclusiveeconomic zones of Pacific isla nds. Hence, this revenue source is recorded a s primary income, ra ther than exports, in the balance of payments.
} 
As a gateway to trade, ports play a critical role in the economic activity of Pacific islands. Verschuur, Koks, and Hall (2021b) combine vessel tracking data with bilateral trade data and input-output tables to show that small island states rely disproportionally on maritime transport for both imports and exports. In some cases, they find that up to 43.5 percent of economic activity can be dependent on trade going through a single port. Pacific islands typically have one or two international ports, which, combined with their large import dependencies, make their gateway ports critical for the islands' economies.

The bulk of the general cargo handled by shipping services in the Pacific are nowadays carried in containers, as elsewhere in the world, and are transported on regulated, scheduled services operating on mostly fixed routes (ADB, 2007). Moreover, even though Pacific islands are dispersed across a wide geography, they are served by only a few container lines ("sea locked"). The UNCTAD's liner shipping connectivity index (LSCI) shows that the Pacific islands are some of the least connected countries in the world in terms of maritime transport (Figure 2). ${ }^{6}$ For example, seven shipping services and 14 port moves would be necessary to export a container from some Pacific islands to Atlantic islands for one trade transaction (UNCTAD, 2020).

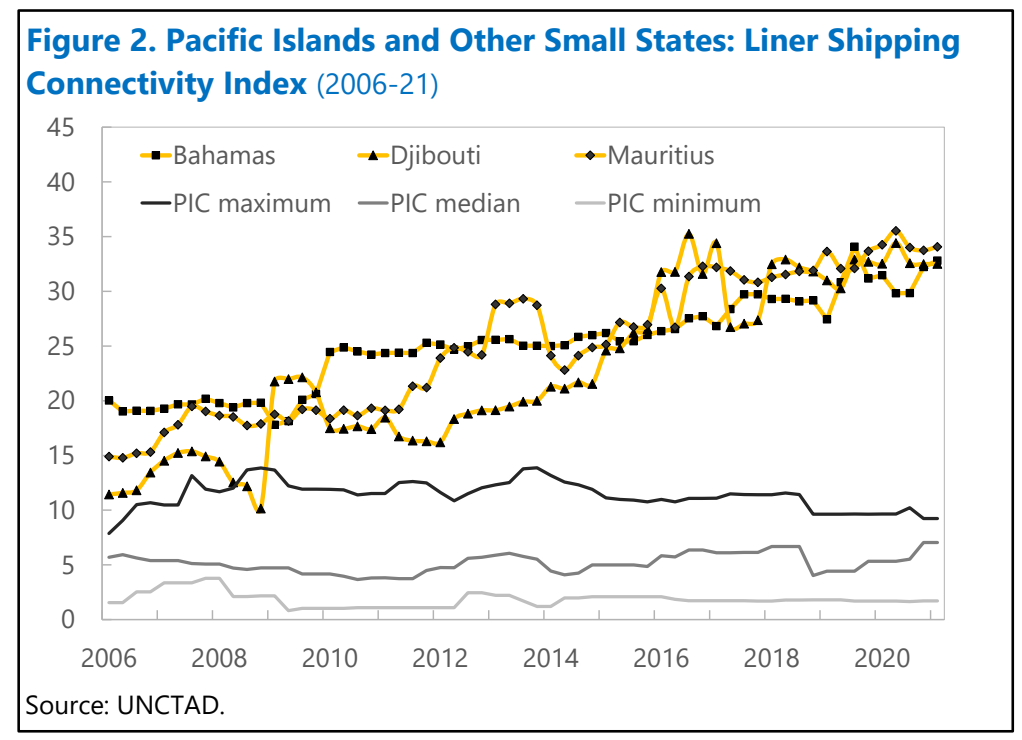

As with other small island states, most important trade flows for Pacific islands are associated with a hub-and-spoke model of container flows. In this model, container ships arrive in transshipment hubs - Guam in the North Pacific and Fiji in the South Pacific - after which containers are moved onto smaller feeder vessels that serve the smaller and more distant ports through a "string" service (Box 2).

\footnotetext{
${ }^{6}$ The Liner Shipping Connectivity Index (LSCI) captures how well countries a re connected to global shipping networks. It is computed by UNCTAD based on five components of the maritime transport sector: number of ships, their container-carrying ca pacity, maximum vessel size, number of services, and number of companies that deploy container ships in a country's ports.
} 


\section{B. Limited Statistical Capacity}

Similar to other small island states with limited resources, Pacific island states tend to have relatively low statistical capacity, which hinders their ability to produce timely or frequent macroeconomic indicators. About half of the Pacific islands are fragile states, defined by the IMF as having weak institutional capacity measured by the World Bank Country Policy and Institutional Assessment (CPIA) score. For the most part, GDP data are published only on an annual basis, usually with a long lag (up to a year or more) and without an expenditure composition. This contrast with other countries in Asia where GDP data are often available quarterly within a few months and typically with an expenditure composition that helps highlight the main drivers of the economy (i.e., consumption, investments, net exports).

The limited availability of timely and high-frequency macroeconomic indicators makes policymaking more difficult in the Pacific islands, as it is harder to detect tuning points in the economy. Such indicators would be useful during normal times - when policymakers are trying to formulate budgets or adjust policies in the absence of timely data - as well as extreme events, such as natural disasters that are frequent in the region.

In this context, one of the few pieces of hard data on economic activity for Pacific islands is imports, given the ease of measurement and Pacific islands' high reliance on imported goods. Indeed, Figure $3 \mathrm{~A}$ shows that there is a positive and usually very high correlation between merchandise imports and GDP for most Pacific islands.

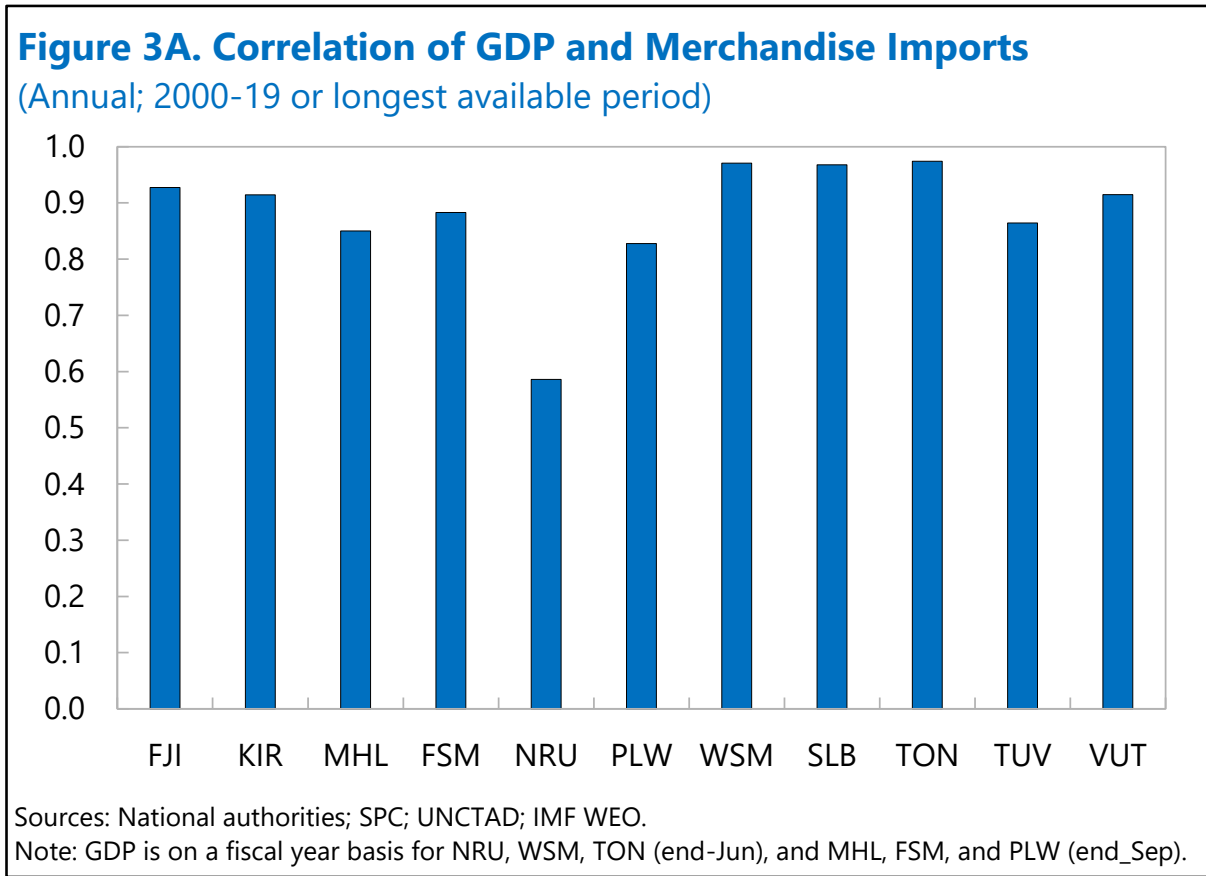


Nevertheless, even data on merchandise trade are subject to long delays in publication for most Pacific countries. Figure 3B shows that more than half of the Pacific island countries publish merchandise trade data with a lag of 12 months or more. In some cases, using "mirror data" from the IMF Direction of Trade Statistics (DOTS) or bilateral sources may provide timelier information but, in general, they do not match the official data closely, possibly due to the extent of transshipment and re-export involved in Pacific regional trade.

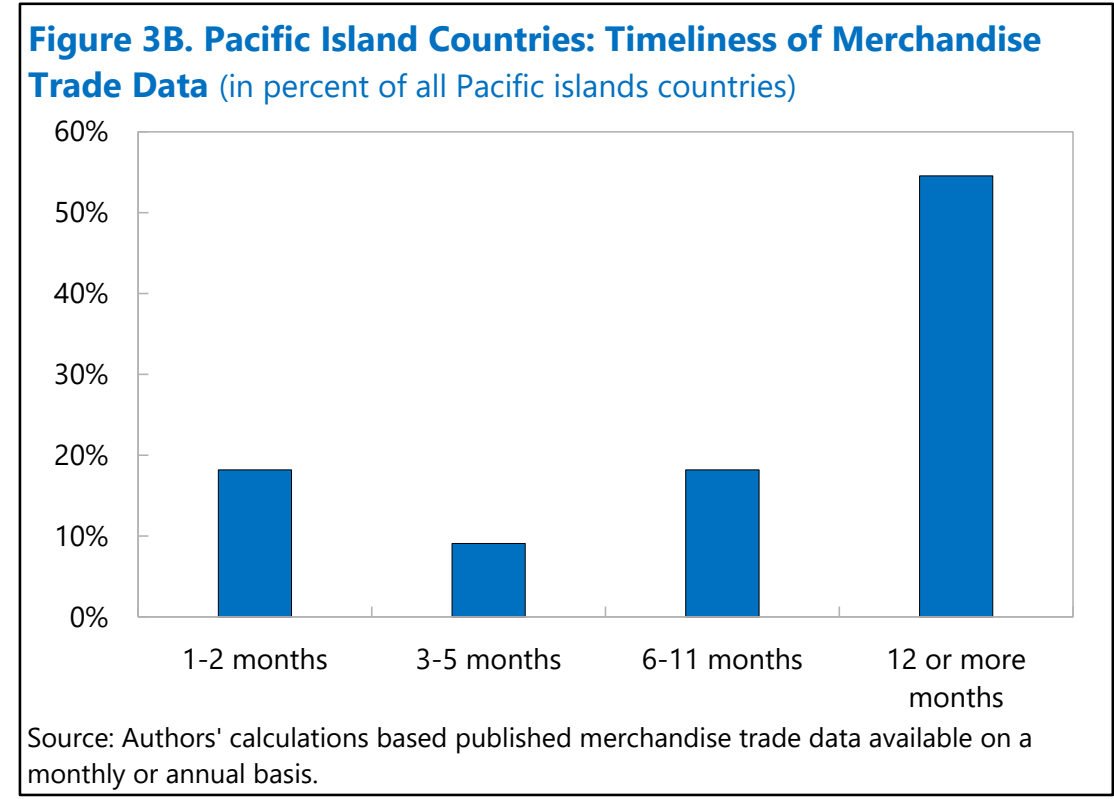

Given these significant data gaps and the importance of trade for the economy, vessel-based high-frequency indicators of trade can complement official statistics on merchandise trade and help track economic activity.

\section{Vulnerability to Climate Change and Natural Disasters}

The Pacific islands are highly vulnerable to climate change and natural disaster risks (Figure 4). The combination of location and small size heightens their vulnerability to rising sea levels and weather-related extremes such as cyclones, hurricanes, and floods.

Cabezon et al. (2015) provide a detailed assessment of Pacific islands' vulnerability to natural disasters. They show that the region has experienced about 2,400 tropical cyclones in 60 years and their frequency has increased over time, in line with global trends. According to the World Risk Index - a composite measure of a country's exposure to natural hazards and of its ability to cope with them - the Pacific islands rank highest on the risk of suffering a disaster. $^{7}$ Among 171 countries, six Pacific islands rank among the first 16 countries at the

\footnotetext{
${ }^{7}$ The World Risk Index is estimated by for 181 countries a s a product of a country's exposure and vulnerability to extremenatural events. Exposure reflects the likelihood of populations being hit by extreme natural events, such as earthquakes, storms, floods, dra ughts, and sea-level rise. Vulnerability reflect the likelihood of suffering from harm in an extreme natural event considering coping and a daptation mechanisms.
} 
highest risk of experiencing a natural disaster - the first being Vanuatu. In recent years, damages and losses have averaged (median) 9.5 percent of GDP for Pacific islands and over 30 percent of GDP in some cases (e.g., Cyclone Evan hitting Samoa in 2012; Cyclone Pam hitting Vanuatu and Tuvalu in 2015; Cyclone Gita hitting Tonga in 2018).

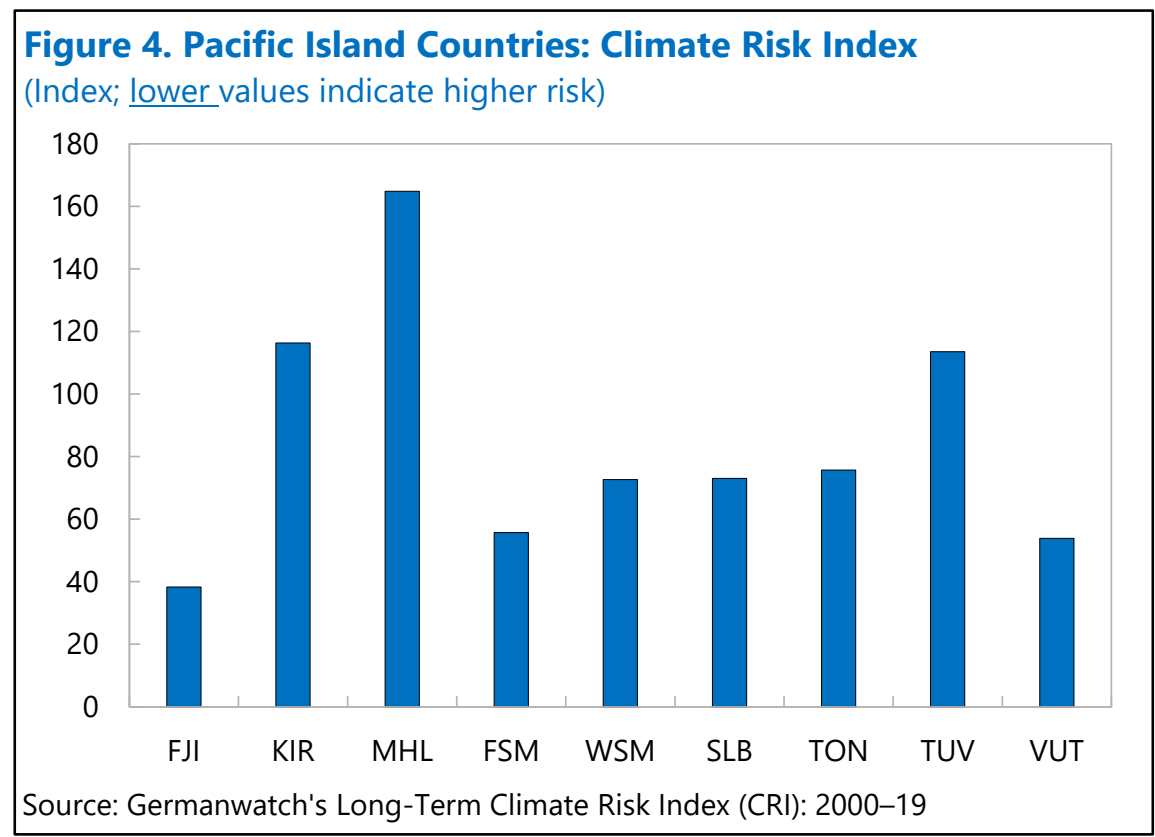

Most recently, in April 2020, severe tropical Cyclone Harold struck Fiji, Solomon Islands, Tonga, and Vanuatu, causing significant losses and damages including to port infrastructure and jetties, as the COVID-19 pandemic made the delivery of emergency support and relief even more challenging. More information on countries' vulnerability to natural disasters can be found in the IMF's Climate Change Indicators Dashboard.

In this context, climate change mitigation and adaptation are important priorities for Pacific islands (Box 1). Verschuur et al. (forthcoming) estimate that every year, 1 to 6 percent of the Pacific islands trade can be disrupted by climate extremes and natural disasters such as typhoons, coastal flooding, earthquakes, with Guam and the Northern Mariana Islands identified as the most at-risk islands.

The impact of natural disasters on ports can be significant and multifaceted. A port disruption can first reduce the amount of freight a port can process for a certain duration, causing delays, the depreciation of goods and, in case cargo is re-routed, additional transportation costs (Achurra-Gonzalez et al., 2019). Verschuur, Koks, and Hall (2020) use vessel tracking data to analyze past port disruptions due to natural disasters, evaluating 141 incidences of disruptions across 74 ports and 27 disasters. Results show a median disruption duration of six days with a ninety-fifth percentile of 22.2 days. All analyzed events show multiple ports being affected simultaneously. Furthermore, a port disruption does not just affect the port 
itself but sometimes the global trade network. For example, Typhoon Maemi in 2003 left the Port of Busan inoperable for 91 days (Becker et al., 2018) disrupting global trade (Lam et al., 2017). Cyclone Yasi in 2011 closed the port of Brisbane for 10 days (Cahoon et al., 2016), causing losses and damages for the national and regional economies.

This all highlights the importance of having high-frequency data to monitor the impact of natural disasters, including on ports and trade, which could in turn assist policymakers and international organizations provide timely responses to shocks. Many Pacific island countries rely on trade and/or consumption taxes for a significant proportion of national government revenues. Almost 62 percent of the Pacific Islands' tax revenue comes from taxes on goods and services, compared to between 32 and 55 percent in the OECD, Asia, Latin America and the Caribbean, and Africa (OECD, 2020). Hence, disruptions to trade flows could lead to reduced tax revenue, with implications for public finances and the ability of government to maintain public services. 
Box 1. Vulnerability of Pacific Island Ports to Climate Change and Natural Disasters

The Pacific islands are situated in one of the most disaster-prone geographical areas. The pandemic was a new setback for Pacific islands already experiencing climate change-related extreme weather events, such as Cyclone Harold in April 2020. Building resilience of Pacific islands against climate-related risks, including with regard to maritime transport chains, is therefore critical to maintain essential international trade flows (UNCTAC, 2020).

Some Pacific islands, such as Kiribati, Marshall Islands, and Tuvalu, have very low elevation (as low as 2 meters on average) and are increasingly exposed to floods and coastal erosion. IMF (2021a) estimates that investment needs for climate-proofing infrastructure to average 3.3 percent of GDP annually for the Asia Pacific region during the next decade, with the amount being much higher for some Pacific island countries. While for some countries this may entail only upgrading new investment projects to make them more climate resilient, which is relatively inexpensive, for others, it may mean retrofitting existing climate-exposed critical assets or developing coastal protection infrastructure, both of which are significantly more expensive. The main ports in the Pacific, built in the 1970s when trade began to expand, are reaching the end of their economic lives under the design codes of that time (ADB, 2019). Hence, much of the critical infrastructure in the region is due for an upgrade to adopt to risk from cyclones, floods, storm surges, and sea level rise.

Ports are not only a gateway of international trade, but also play a "lifeline" function in the aftermath of a disaster by supporting subsequent relief efforts. Therefore, an important consideration in port design is to ensure the basic port facilities can withstand the impacts of the disaster so that the port remains operational in the aftermath of such events (ADB, 2020).

Such approaches are increasingly being adopted by the port renewal and expansion plans in the Pacific (ADB, 2019 and 2020). In Nauru, the ADB is developing a climate-resilient port that can operate year-round. The new port, co-financed by the Green Climate Fund and the Government of Australia, will provide a much-needed reliable lifeline for the residents of the small island state. At the Honiara Port in Solomon Islands, a wharf has been selected as the lifeline wharf and its design checked to the more rigorous standards required for a lifeline structure. Similar approaches are been considered in the design of new port facilities in Samoa (Apia) and Tonga (Nuku'alofa).

Global initiatives in greener shipping could also affect Pacific islands. In 2018, the IMO adopted its initial greenhouse gas (GHG) emission strategy that envisages a reduction in carbon intensity of international shipping by at least 40 percent by 2030. Initiatives such as the Getting to Zero Coalition, supported by UNCTAD, also aim at reducing $\mathrm{CO}_{2}$ emissions from shipping to net-zero. A ship's emissions depend on numerous factors, including the fuel used and speed. AIS data-in combination with information about the ship's engine and fuel—can help assign $\mathrm{CO}_{2}$ emissions to the country of the vessel's flag or the country's waters where the $\mathrm{CO}_{2}$ is being emitted. This, in turn, could in principle be used to collect levies proportional to the emissions by the flag state or the state where the emissions take place (Parry et al. 2018). 


\section{Data AND Methodology}

\section{A. Data}

We derive daily estimates of port-level trade flows (imports and exports) from December 2018 to February 2021 for 30 ports across 11 Pacific island countries using geospatial location data. To do this, we use real-time data on vessel movements-AIS signals of vessels - as our primary data source.

The AIS was originally developed by the International Maritime Organization (IMO) in 2004 as an outcome of amendments to the International Convention SOLAS (Safety of Life at Sea) in 2002. It is a self-reporting system, which allows vessels to periodically broadcast their identity, navigation, position data and other characteristics. The AIS has been made compulsory for all international commercial ships with gross tonnage of 300 or more tons (i.e., virtually all commercial ships) and all passenger ships regard less of size.

There are three main types of information in AIS messages. AIS broadcasts voyage-related information (including ship location, speed, course, heading, rate of turn, destination, draft, and estimated arrival time), static information (including ship ID, ship type, ship size and dimensions), and dynamic information. Dynamic information such as the positional aspects (latitude and longitude) is automatically transmitted, depending on the vessels' speed and course. The signals can be picked up by satellite or terrestrial receivers. For ships in open seas, however, the signals can only be picked up by satellite receivers as terrestrial receivers typically cover only about 15-20 nautical miles from the coast. For island states, satellite data tend to be much more reliable as the coverage of terrestrial receivers can be low (or nonexistent) for these smaller countries. Terrestrial receivers are useful for congested ports where congestion may make it difficult for satellites to capture all emitted mess ages. Additional information on AIS data can be found in Arslanalp et al. (2019), Verschuur et al. (2020), and the UN's AIS Handbook.

The UN has recently made available satellite based AIS data through the UN Global Platform (UNGP) to national and international agencies that are members to the UN-CEBD (UN, 2021). The platform contains live data and global archive data from December 1, 2018. A dedicated website details how to access and utilize the platform with the main objective that others would be able to replicate calculation of indicators without the need to procure IT infrastructure and AIS data themselves. AIS data at the UNGP are provided by ExactEarth, which collects AIS messages from two different satellite constellations, with more than 65 AIS equipped satellites. ExactEarth complements this information with data collected by FleetMon through terrestrial receivers.

AIS data have been used successfully for a variety of fields and applications, such as port statistics, port performance analysis, economic trade estimation, fisheries monitoring, and maritime $\mathrm{CO}_{2}$ emissions. Originally, AIS was designed to monitor vessel location and movement primarily for traffic management, collision avoidance, and other safety 
applications for port authorities and harbor masters. However, over time, there have been many other uses. UNCTAD, for example, already provides statistics on port calls building on AIS data provided by MarineTraffic. In addition, research on the use of AIS for official statistics is part of the European statistical system's ESSnet Big Data project-in fact, Denmark and Norway already publish daily number of vessels visiting Danish and Norwegian ports using AIS data. Similarly, the UK's Office for National Statistics publishes monthly indicators of shipping activity at UK ports, based on AIS data, as part of its faster indicators of economy activity. Others have used the AIS data for monitoring fishery activities (Vespe et al., 2016; Global Fishing Watch), identifying ships in distress (Hoffmann Pham, Boy, and Luengo-Oroz, 2018), and calculating emissions of greenhouse gasses by ships (Hensel, Uge, and Jahn, 2020). Finally, we and others have used it to nowcast or forecast merchandise trade (Arslanalp et al., 2019; Cerdeiro et al., 2020; J.P. Morgan, 2020; Verschuur et al., 2020; Stamer, 2021), as well as to track seaborne oil and commodity trade (Adland, Jia, and Strandenes, 2017; Oceanbolt, 2020). ${ }^{8}$

There are several challenges with using AIS data. First, ships can turn off their AIS transponder to avoid being detected. Strictly speaking, this is not legal and is mostly limited to fishing vessels conducting illegal fishing or oil tankers circumventing international sanctions, usually in international waters. It is not common for container and other cargo ships (which is the focus of our study) entering a country's port. In fact, in most jurisdictions, port authorities make it mandatory for ships entering a port to keep their AIS transponders on at all times for the safety all vessels in the port. Second, the AIS data do not have information about the ship's carrying capacity (i.e., deadweight tonnage) and maximum draft. To fill this gap, we use ship registry databases from FleetMon and IHS Markit (the latter is available from the UNGP), with information for around 38,000 vessels.

Finally, a potentially more serious challenge with AIS data is that some information is entered manually and, hence, may have human errors. This is expected as AIS was intended originally for safety at sea, not for producing statistics. For our purposes, the key issue is that the crew may not always update the draft information after a ship leaves the port. The draft is the vertical distance between the waterline and the bottom of the ship's hull and is a measure of the payload of the vessel. However, our algorithm uses techniques to address this issue. Particularly, the missing information can be backtracked or imputed in most cases, given the wealth of information in the AIS data (as described in the next section). For any remaining cases, if measurement errors are idiosyncratic, they should wash out when aggregated due to the law of large numbers.

\footnotetext{
${ }^{8}$ AIS data have a lso been used for modeling purposes. Brancaccio et al. (2020) use AIS data to develop a model that delivers endogenous tra de costs. Heiland et al. (2019) use the data to construct a network of ports and estima te the welfare ga ins from the 2016 Pa nama Canal expansion. Ga napati, Wong, andZiv (2020) build an endogenous model of hub ports incorporating route choice by exporters within a Ricardian setting.
} 


\section{B. Methodology}

Building on Arslanalp et al. (2019) and Verschuur et al. (2020), we develop an algorithm to estimate trade flows for Pacific island countries based on vessel data. The algorithm significantly advances estimation techniques of previous studies, particularly by employing ways to overcome challenges with the estimation of cargo payloads, using detailed information on shipping liner schedules (Box 2) to validate port calls, and applying countryspecific information to define port boundaries. Unlike previous studies, we do not need to make assumptions on ballast water or assume cargo weight changes linearly with the ship's draft. Finally, the results can be replicated transparently by other researchers using data from the UN Global Platform, unlike other studies which are based on proprietary data from commercial data providers that make their results hard to verify.

To overcome challenges with the estimation of cargo payloads, the algorithm employs two techniques (backpropagating and historical averaging) to deal with a key measurement issue in the AIS data. As noted, the ship's crew may not always update the draft information before a ship leaves the port. However, the draft information gets updated when the ship is about to enter the next port of call, as port authorities require vessels to broadcast their latest information before entering a port (for safety reasons). Accordingly, the missing departure draft can be backtracked from the arrival draft at the next port of call (backpropagating). In our experience, this technique successfully handles two-thirds of the port calls with missing information. For the remaining one-third, the algorithm uses a second technique-it imputes the draft change based on the historical cargo delivery of the vessel based on its history of port calls at a given port (historical averaging). The combination of these two techniques deals with all cases with missing information and improves on other studies that inadvertently assume no trade activity takes place when the draft information does not get updated before port departure.

To do this, we have manually mapped 30 port areas across 11 Pacific island countries. It is important to do this manually and carefully for small states, as machine-learning techniques may fail when the training sample size is small. ${ }^{9},{ }^{10}$ Fortunately, most Pacific island ports are covered by the U.S. National Geospatial-Intelligence Agency's World Port Index (WPI) - a publicly available database that contains the proximate location (longitude and latitude) and

\footnotetext{
${ }^{9}$ Cerdeiro et al. (2020) note that a popular spatia l clustering a lgorithm (DBSCAN) struggles to find clusters with significantly differing densities - that is, it may miss some low-traffic ports or lump them together with nearby high-traffic ports. To overcome this issue, Cerdeiro et al. (2020) first use this unsupervised ma chine-learning technique (i.e., without a ny tra ining data) to define port boundaries to identify potential port calls. To tea se out actual port calls from this set of potential port calls, they then use fouryears of daily official vessel entrances recorded by U.S. customs at U.S. ports to tra in a cla ssifier that returns a prediction of whether a potential port call is an actual port call or not. This cla ssifier is then a pplied globally to other countries.

${ }^{10}$ Cerdeiro et al. (2020) notethat no machine learning a lgorithm can handle all possible real-life situations. They note that and deep domain knowledge of the particular ports or the specific segment of the maritime shipping industry is needed to improve the performance of these techniques. Still, we found them to be a useful cross-check for our port calls.
} 
physical characteristics of major ports around the world. We cross-check and refine, as needed, the central location of ports using Google Maps. The full list of port locations for Pacific islands is shown in Annex Table 1.

\section{Box 2. Shipping Lines Serving the Pacific Islands}

The bulk of cargo imports in the Pacific are carried in container ships (ADB, 2007). Consequently, it is important to understand the major shipping routes connecting Pacific island states, which has a high degree of concentration with three main shipping lines/consortia providing shipping services. This box provides basic information on the shipping routes and vessel fleets of each shipping line. Further information can be found in the links provided, which was used extensively in this paper in the analysis of the AIS data from the UN Global Platform and validate the results.

Kyowa Shipping provides three liner services via Guam, Korea (Busan) and Japan connecting European and Asian ports to the Pacific Islands. In particular, the Micronesia Service provides service to Micronesian ports, mainly using three multi-purpose vessels of 12000 DWT. Ports of call are Palau (Koror), Federated States of Micronesia (Yap, Chuuk, Pohnpei, Kosrae) and Marshall Islands (Majuro, Kwajalein, Ebeye). Ports visits take place about every two weeks. The South Pacific Service provides service to the South Pacific with four multi-purpose vessels of DWT 18000 DWT. Ports of call are Kiribati (Tarawa), Solomon Islands (Honiara), Vanuatu (Port Vila, Santo), New Caledonia (Noumea), Fiji (Suva, Lautoka), Tonga (Nuku'alofa), Samoa (Apia), American Samoa (Pago Pago), and Tahiti (Papeete). Finally, the Papua New Guinea/Australia Service provides service with two multi-purpose vessels of 8500 DWT. Ports of call are Papua New Guinea (Lae, Port Moresby, Rabaul) and Australia (Townsville). It has a partnership with the US-based Matson shipping company.

Neptune Pacific Direct Line was formed in 2020, when Neptune Pacific Line acquired Pacific Direct Line (PDL), bringing together two of the South Pacific's leading shipping companies and offers a range of shipping service linking the South Pacific Islands with Australia and New Zealand. It has a cooperation with the government of Samoa and owns a 50 percent controlling interest in Pacific Forum Line (PFL). It has vessels calling in Vanuatu (Vila and Santo), Fiji (Suva and Lautoka), Tonga (Nuku'alofa), Samoa (Apia), Tahiti (Papeete), Tuvalu (Funafuti), Solomon Islands (Honiara), as well as Kiribati, Marshall Islands, and Nauru. It has a partnership with the Mariana Express Lines (MELL), through which it services Palau and Yap out of Guam.

Swire Shipping operates 13 liner services connecting over 400 ports via an extensive network of services in the Asia-Pacific region. Among these services, the Polynesia Line operates a shipping network from the U.S. West Coast to the Pacific Islands, offering a fortnightly service from Los Angeles and Oakland in the United States to Tahiti, Tonga, Samoa, American Samoa, and the 
wider Pacific. The Australia Pacific Islands line provides a multi-purpose liner service accepting all types of containerized, breakbulk and project cargo between East Australia and New Caledonia, Vanuatu, Fiji, Samoa, and Tonga. Similarly, New Zealand Eastern Pacific Islands line provides service between Auckland and Tonga, Fiji, Samoa, Tahiti, the Cook Islands, and Niue. The Pacific North Asia line provides services between North Asia and the Marshall Islands, Kiribati,

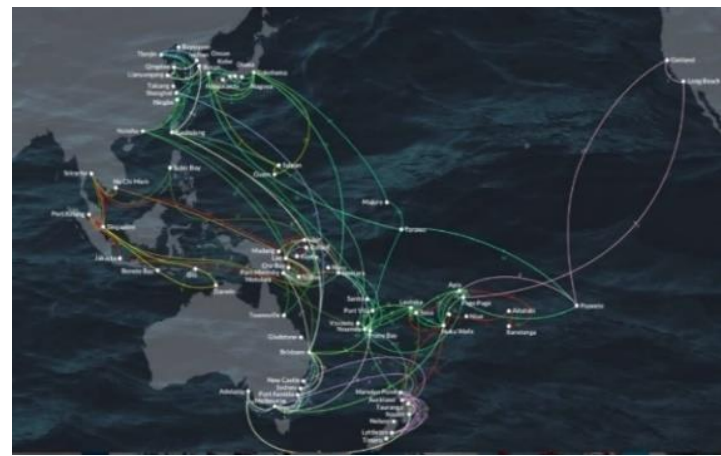
Vanuatu, Solomon Islands, New Caledonia, Fiji, Tonga, Samoa, and Tahiti.

Once we identify the central location of a port using WPI and Google Maps, we generate a port boundary (polygon) by looking at vessel movements in and around the port using satellite imagery (see Figure 5A below examples for Nauru and Samoa). ${ }^{11}$

Figure 5A. Selected Pacific Islands: Port Boundaries

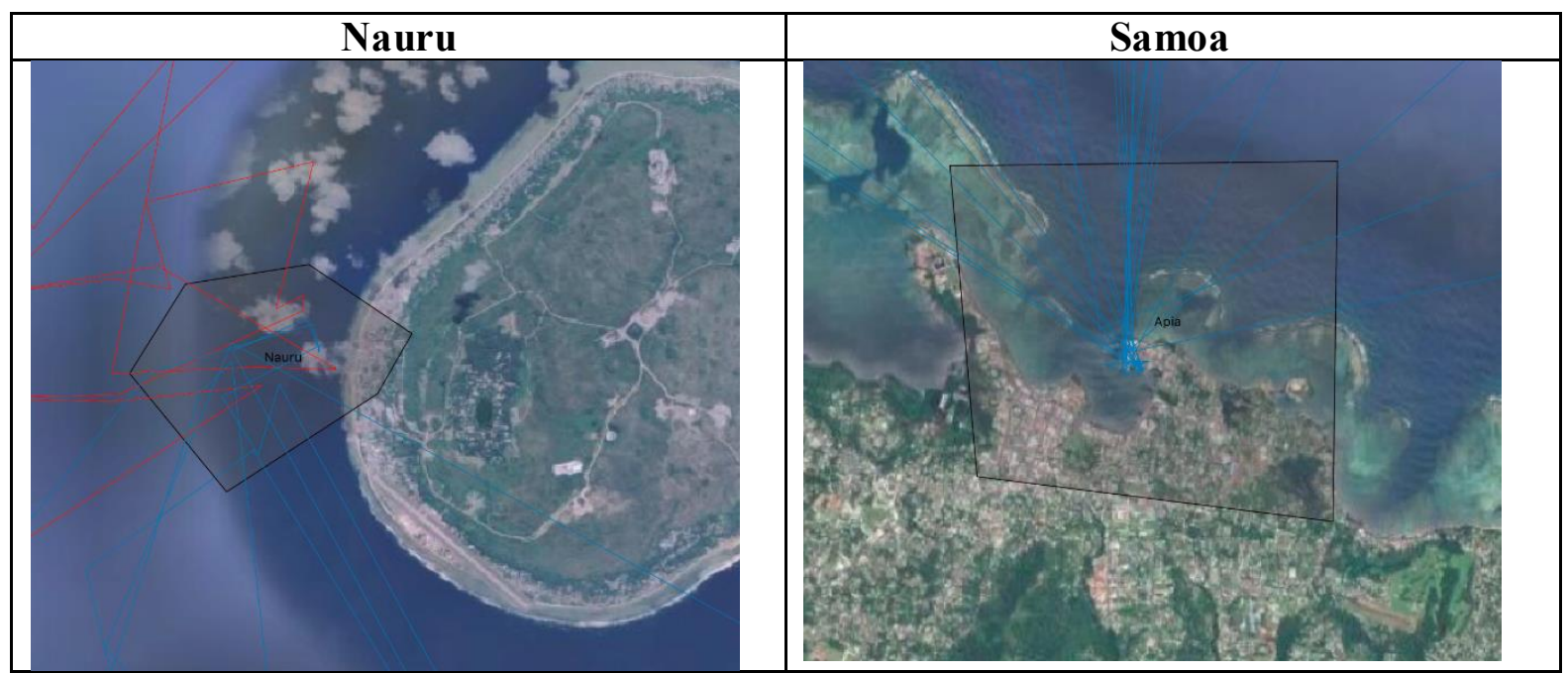

These 30 ports include all major international ports of Pacific island countries and hence cover the complete share of their maritime trade (Figure 5B). They include Suva, Lautoka, Malau, Nabouwalu, and Savusavu ports for Fiji; Betio/Tarawa and Kiritimati ports for Kiribati; Majuro and Ebeye ports for Marshall Islands; Yap, Chuuk, Pohnpei, and Kosrae ports for the Federated States of Micronesia; Nauru port for Nauru; Malakal port for Palau; Apia port for Samoa; Honiara, Noro, Mbulo, Ndora, Gizo, Rennell Island, Lughughi, Ringgi,

\footnotetext{
${ }^{11}$ We also experimented with a pre-determined port boundary - a circle with an a ppropriately set ra dius around the central port locations identified in the paper(Annex Table 1). This approach generates similar results, given the rela tively simple structure of Pacific isla nd ports that have not changed much since the 1970s (Box 1).
} 
and Seghe ports for the Solomon Islands; Nuku'alofa and Neiafu ports for Tonga; Funafuti port for Tuvalu; Port Vila and Santo/Luganville ports for Vanuatu.

Figure 5B. Pacific Islands: Major International Ports
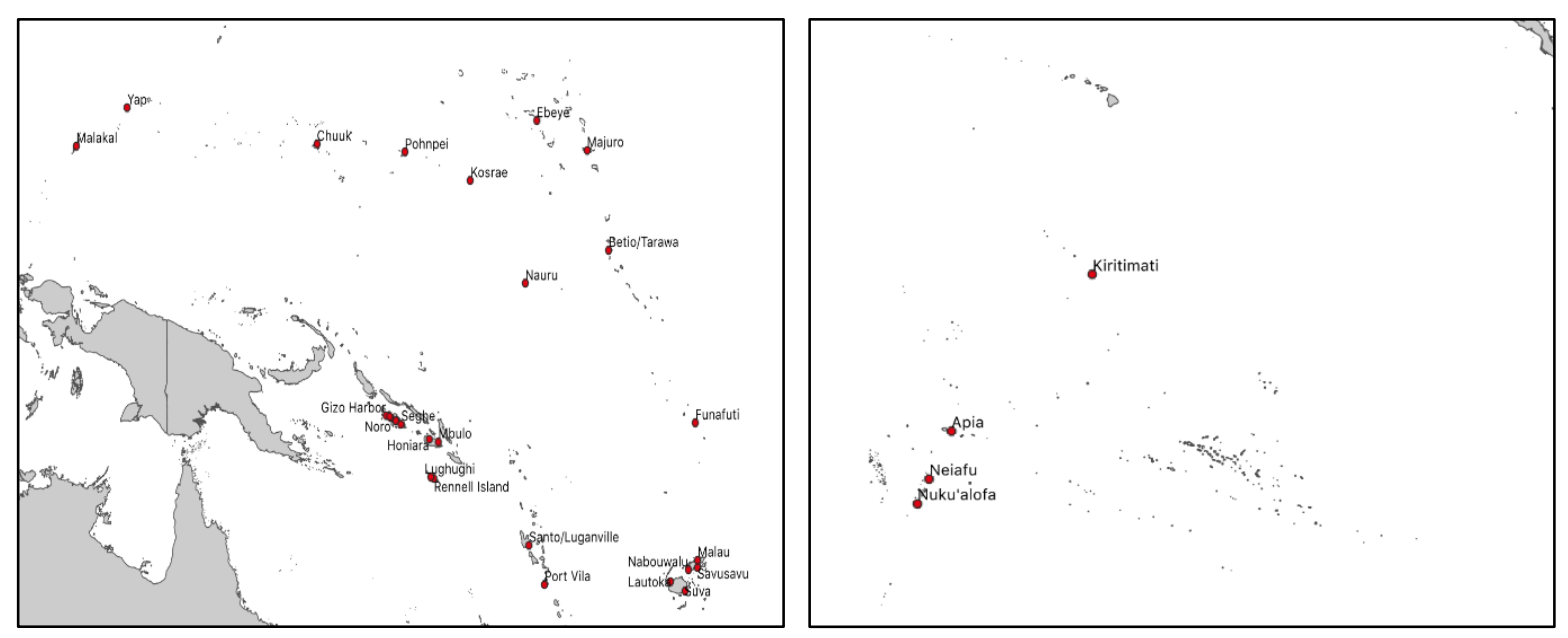

As in Arslanalp et al. (2019) and Verschuur et al. (2020), the algorithm implements filtering criteria to extract port calls that contribute to trade. First, we focus on container ships- the main engine of seaborne trade in the Pacific - vehicle carriers, and bulk carriers (relevant for Fiji, Nauru, and Solomon Islands as commodity-exporters). Fuel tankers are not included, as Pacific countries import a significant portion of fuel for re-exports (for visiting foreign vessels and airlines) and, in some cases, import them for transshipment. As noted earlier, fishing vessels do not contribute to trade as they are mostly foreign-owned. Second, port calls with a turnaround time of less than 5 hours and no draft change between the current and next port are excluded to filter out vessels in transit (i.e., vessels that visit a port for reasons other than loading and discharging cargo, such as anchoring, refueling or provisioning). This results in 3605 port calls by 260 vessels during 2019-20 (Table 1). ${ }^{12}$

Table 1. Pacific Island Countries: Port Calls by Type of Ship During 2019-20

\begin{tabular}{|lcccccccccccc|}
\hline & FJI & KIR & MHL & FSM & NRU & PLW & WSM & SLB & TON & TUV & VUT & Total \\
\hline Containerships & 841 & 113 & 263 & 297 & 22 & 126 & 295 & 330 & 297 & 30 & 236 & $\mathbf{2 8 5 0}$ \\
Vehicle carriers & 50 & 0 & 0 & 0 & 0 & 0 & 0 & 0 & 0 & 0 & 0 & $\mathbf{5 0}$ \\
Bulk carriers & 68 & 0 & 0 & 0 & 9 & 0 & 0 & 615 & 0 & 0 & 13 & $\mathbf{7 0 5}$ \\
Total & $\mathbf{9 5 9}$ & $\mathbf{1 1 3}$ & $\mathbf{2 6 3}$ & $\mathbf{2 9 7}$ & $\mathbf{3 1}$ & $\mathbf{1 2 6}$ & $\mathbf{2 9 5}$ & $\mathbf{9 4 5}$ & $\mathbf{2 9 7}$ & $\mathbf{3 0}$ & $\mathbf{2 4 9}$ & $\mathbf{3 6 0 5}$ \\
\hline
\end{tabular}

To estimate the amount of trade, one needs information on the carrying capacity and the type of vessels. AIS data includes information on the vessel length, width, draft, ship type (e.g., cargo or tanker). However, it does not include data on the vessel's maximum (design) draft,

\footnotetext{
${ }^{12}$ The a lgorithm and the defined port boundaries are a vailable from the authors upon request.
} 
carrying capacity (i.e., deadweight tonnage, DWT) or and ship subtype (e.g., oil tanker, vehicle carrier). Here, we use the ship registry databases from FleetMon and IHS Markit.

Finally, we collect information on the block coefficient of vessels based on their subtype and DWT. The block coefficient is ratio of volume displacement of the vessel compared to a rectangular block with the same dimensions. It depends on the characteristic of the hull of a vessel. Block coefficients for vessel types and multiple DWT indicators per type are obtained from DHI (2018) and added to database based on the closest match of DWT per vessel type.

We use the vessel information (length, width, draft, capacity, block coefficient) to estimate the payload (or utilization rate) of the vessel when entering and leaving the port boundary.

Following Jia et al. (2019), the utilization rate for a given reported $(r)$ draft can be estimated given the design $(d)$ vessel characteristics:

$$
\mu_{r}=\frac{\left(C b_{r} d_{r}-C b_{d} d_{d}\right) L W \rho_{w}+D W T}{D W T}
$$

where $L=$ length; $W=$ width; $d_{d}=$ design (maximum) draft; $d_{r}=$ reported draft; $C b_{d}=$ block coefficient at design draft; $C b_{r}=$ block coefficient at reported draft; $\rho_{w}=$ average density of salt water (1.025 tons $/ \mathrm{m} 3) ; D W T=$ deadweight tonnage of vessel (i.e. maximum carrying capacity of the vessel when it is floating at its maximum draft); and $\mu_{r}=$ vessel payload at reported draft. $\mathrm{Cb}_{\mathrm{r}}$ can be estimated using:

$$
C b_{r}=1-\left(\left(1-C b_{d}\right){\frac{d_{r}}{d_{d}}}^{1 / 3}\right)
$$

The utilization can be found based on the draft when entering $\left(d_{r, \text { in }}\right)$ and the draft when leaving the port $\left(d_{r, \text { out }}\right)$. In some cases, the draft is not updated when leaving the port, but only when entering the next port of call. Hence, we backpropagate $d_{r, \text { out }}$ when no draft change is observed:

$$
d_{r, \text { out }}=\left\{\begin{array}{clc}
d_{r, \text { in, next }} & \text { if } & d_{r, \text { in }}=d_{r, \text { out }} \\
d_{r, \text { out }} & \text { if } & d_{r, \text { in }} \neq d_{r, \text { out }}
\end{array}\right.
$$

with $d_{r, \text { in, next }}$ the incoming draft at the next port of call.

By construction, the utilization rate ranges from zero to 100 percent. In practice, however, we observe that the utilization rate is between a positive number (e.g., 30-40 percent) and 100 percent since there is usually ballast water in the ship (i.e., water held in the ballast tanks) to provide stability and maneuverability to the ship (especially when it is not carrying heavy enough cargo). In this regard, the utilization rate already captures the ballast water in the ship - that is, we do not need to make a separate assumption on ballast water levels. 
Trade flows are then derived from the differences in the utilization rate when entering $\left(\mu_{r, i n}\right)$ or leaving a port $\left(\mu_{r, \text { out }}\right)$. The change in the vessel payload (in percentage points) multiplied by the vessel's deadweight tonnage (carrying capacity) in metric tons is the resulting trade flow (either import or export) in metric tons. This calculation is not affected by ballast water as long as ballast water does not change within the port boundary. ${ }^{13}$

In some cases, even after correcting the outgoing draft, no draft change is observed. In some situation this may be correct, but in the majority of cases this is because the vessels' dynamic information is not updated. To correct for this, we estimate the average trade flow associated with a specific vessel in a specific port, as most vessels are either importing or exporting goods at a port of interest. In short, we can write the estimated trade flow (T) as:

$$
T=\left\{\begin{array}{ccc}
\left(\mu_{r, \text { out }}-\mu_{r, \text { in }}\right) D W T & \text { if } & d_{r, \text { in }} \neq d_{r, \text { out }} \\
T_{\text {average }} & \text { if } \quad d_{r, \text { in }}=d_{r, \text { out }}
\end{array}\right.
$$

With $\mathrm{T}_{\text {average }}$ the average of all non-zero trade flows observed for a given vessel at a given port based on the vessel's history of port calls. $T_{\text {average }}$ is only assigned to vessels that are not in transit. Using the definition adopted, imports are then defined as all trade flows smaller than zero and exports all trade flows larger than zero.

For Pacific island countries, internal trade takes place through small vessels (i.e., domestic ferries) that transport goods from the country's main port to the outer islands. To take this into account, the algorithm does not include port calls if vessels have only visited one country during the time period. The algorithm also makes use of domain expertise to check for the direction of trade from specialized export ports or by vessel type (e.g., bulk carrier).

Finally, the algorithm makes use of information on liner shipping schedules to improve the accuracy of estimates. As with other small island states, most important trade flows for Pacific islands are associated with a hub and spoke model of container flows. In this model, container ships arrive in large hubs - Guam in the North Pacific and Fiji in the South Pacific - after which containers are moved onto smaller feeder vessels that serve the smaller and more distant ports (Ducruet and Zaidi, 2012). Through a careful study of shipping routes in the region, we identify the key liner shipping companies and their vessel fleets serving the region (Box 2). By doing so, we were able to improve the accuracy of our identified port calls and match official port call data, where available (Box 3). Overall, our indicator of trade explains 89 percent of the variation in available official statistics (Box 4).

\footnotetext{
${ }^{13}$ For container ships (which operate like buses between ports), there is usually no need changeballa st wa ter at the port. In contrast, bulk carriers (which operate like taxis between two ports) may need to adjust balla st wa ter before or after they enter a port, a s they can fully load or unload cargo at a specific port.
} 


\section{Box 3. Country Validations-Quality Assurance of Satellite AIS Indicators}

To verify the quality of our analysis of the AIS data from the UN Global Platform and validate the satellite-based port activity indicators, we compared them with official statistics where feasible. In the cases of Fiji and Nauru, the results matched exactly with the official port call data reported by the authorities. In the case of Samoa, we had a virtual perfect match between the detailed port call data reported by the authorities and data we gather from satellite AIS data. Further information on the available official data can be found in the links provided below.

Fiji provides publicly available information on shipping scheduled and expected arrivals of container ships and cruise ships through the website of Fiji Port, the government owned company that administers international ports of entry. We used the latest available information on the website (for January 2020) to validate our results, which generated a perfect match.

Nauru provides real-time information in incoming container ships through the website of Nauru Maritime and Port Authority (since mid-2020). We used the available information on the website to validate our results, which again generated a perfect match.

Samoa publishes detailed data on cargo shipping ("Cargo Shipping Report") with monthly data on arrivals and departures of container ships. The information is available from 2015 onward. The report is published on the website of the Samoa Bureau of Statistics (SBS) with a lag of 2-3 months. Withstanding some minor differences for a few months, these figures match our annual figures for 2019-20 perfectly. 


\section{Box 4. Comparison with Official Trade Data}

This Box explores the alignment of our trade proxy with official trade data, where available.

In particular, we focus on monthly merchandise trade data for the period 2019-20. The data are available for Kiribati, Palau, and Vanuatu for 2019 and for Fiji, Samoa, Tonga, and Tuvalu for 2019-20 from the SPC's International Merchandise Trade Statistics for the Pacific region based on customs data. We focus on merchandise imports of goods (excluding fuel, aircraft and boats). The data are converted into US dollar for cross-comparability.

Several caveats are in order. First, the official data are in value terms, while our trade proxy is in volume terms by construction. Hence, we should not expect a perfect match between our proxy and the official trade data - unfortunately, there is no monthly trade data for Pacific islands on volume terms that we could use for this comparison, which highlights (again) the data gap issue. Second, in some cases our trade proxy may lead the official trade statistics (e.g., by a month) as the recording of trade by national customs offices tends to be based on by custom declarations - those may take place somewhat after the unloading of goods at the port.

With these caveats in mind, we consider the following panel regression:

$$
x_{i, t}=\alpha_{i}+\beta x_{i, t}^{*}+\varepsilon_{i, t}
$$

Where $\mathrm{x}_{\mathrm{it}}$ is official trade data and $\mathrm{x}_{\mathrm{it}}$, is our trade proxy for country $\mathrm{i}$ and period $\mathrm{t}$. We run the panel regression with and without fixed country effects and the results are summarized below.

Box Table 1. Official and Proxy Trade Data

Sample (Pacific Islands, 2019-20)

\begin{tabular}{lcc}
\hline & $\begin{array}{c}(1) \\
\text { With country } \\
\text { fixed effects }\end{array}$ & $\begin{array}{c}\text { Without country } \\
\text { fixed effects }\end{array}$ \\
\hline Trade proxy & $0.79^{* * *}$ & $1.79^{* * *}$ \\
& 0.15 & 0.16 \\
Constant & $26.53^{* * *}$ & $12.36^{* * *}$ \\
& 2.15 & 3.73 \\
Observations & & \\
Number of countries & 132 & 132 \\
R-squared & 7 & 7 \\
$\quad$ within & 0.89 & 0.89 \\
between & $\ldots$ & 0.58 \\
\hline
\end{tabular}

Source: Authors' estimates.

Notes: Standard errors in parentheses. $* * * \mathrm{p}<0.01, * * \mathrm{p}<0.05, * \mathrm{p}<0.1$

The results suggest that our trade proxy and official trade data are reasonably aligned. The goodness of fit (R-squared) for the panel regression pulling all available data together is 0.89 with or without country fixed effects. 


\section{Tracking Trade in the Pacific During The COVID-19 Pandemic}

In this section, we illustrate the usefulness of our approach by studying the impact of the COVID-19 pandemic on regional trade in 2020. Specifically, we show that our daily indicators of port and trade activity were highlighting a trade slowdown as early as January/February 2020 even before the World Health Organization declared COVID-19 a pandemic (on March 11,2020). As such, these indicators can be useful when policymakers are trying to formulate budgets or adjust policies in the absence of timely data.

Specifically, we analyze vessel traffic data during the year of the pandemic (from January to December 2020) and compare them to the respective period before the pandemic (January to December 2019). ${ }^{14} \mathrm{We}$ find that, although most Pacific islands managed to insulate themselves from COVID-19 infections by closing their borders, they were not insulated from the trade and economic repercussions of the pandemic in the rest of the world.

Figure 6 below provides an overview of the vessel traffic data, illustrating the main changes to the regional trade network. The results point to reduced trade flows across many key transportation routes in the South Pacific, particularly those that connect Pacific island countries with China, New Zealand, and to a lesser extent, Australia.

\footnotetext{
${ }^{14} \mathrm{We}$ undertake a year-over-year comparison to avoid the problem of seasonal fluctuations. In doing so, we make a reasonable assumption that the consumption basket (more specifically, the import basket) does not change significantly from one year to the next. As a result, any la rge changes in volumes from one year to the next should reflect something real a bout the economy and not a shift in the importbasket.
} 
Figure 6. The Impact of COVID-19 Pandemic on Regional Trade in the Pacific

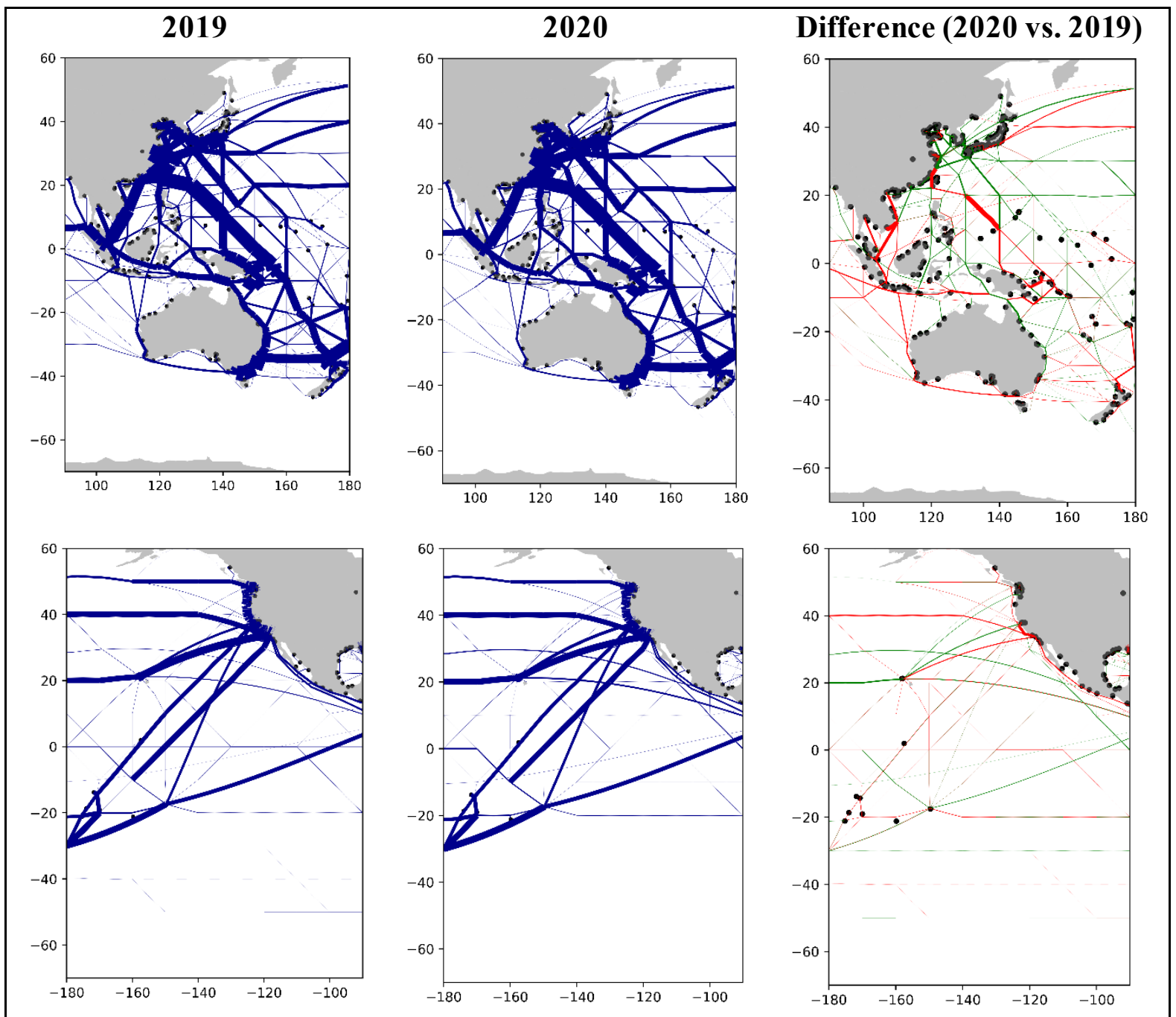

Note: The $\mathrm{x}$-axis shows the la titudes and $\mathrm{y}$-axis shows the longitudes. In theleft and middle columns, the blue lines show the carrying capacity on a certain port-to-port legs, irrespective of direction of tra de. The thickness of the lines represents the capacity of the vessels on those legs. In the right column, the difference between 2019 and 2020 is shown in red if the change in ca pacity is nega tive and green if positive.

Looking at the dynamic evolution of imports, we find that all Pacific islands experienced a decline in imports at the beginning of the pandemic, likely due to supply disruptions.

However, there was a differential evolution of imports between tourism-reliant islands and others in the later stage.

\section{A. Supply Disruptions in the Early Stage}

The data suggest that there was a supply impact of the pandemic due to port restrictions that affected the regional trade network. The main disruption seems to have come from port entry restrictions imposed by Pacific islands starting around March 2020 when the World Health Organization declared COVID-19 a pandemic. In addition, lockdowns imposed by major 
trading partners, notably by China, likely also played a role. ${ }^{15}$ In fact, trade was already falling below 2019 levels by January/February 2020 for most of the region (Figure 7).

The resulting drop in imports had significant adverse effects on the economies of Pacific islands, given their dependence on a broad range of essential goods from abroad. For example, when the first case of COVID-19 was recorded in Lautoka, Fiji, in March 2020, the port was closed and all ships were diverted to Suva, Fiji, or elsewhere. Shortages were reported in subsequent months, including a few instances of food shortages. For example, in June 2020, certain islands in Kiribati began to experience shortages of food products, as ships had not visited some of the islands since March 2020 (UNCTAD, 2020). ${ }^{16}$

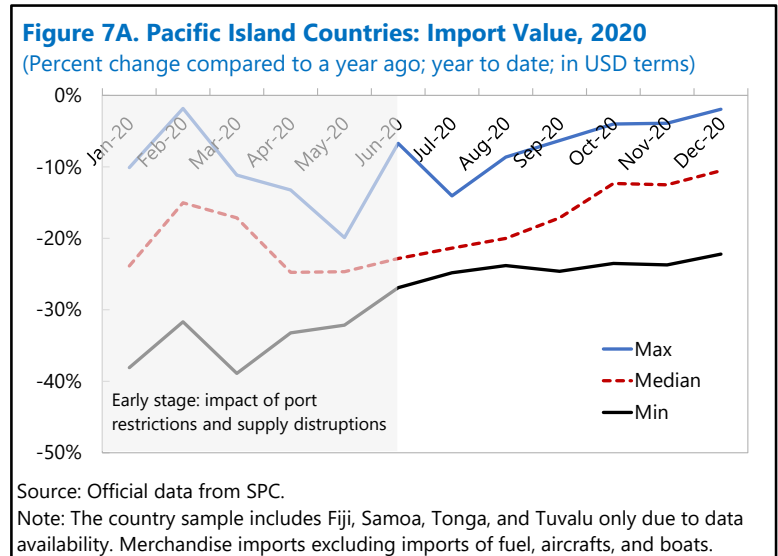

availability. Merchandise imports excluding imports of fuel, aircrafts, and boats.

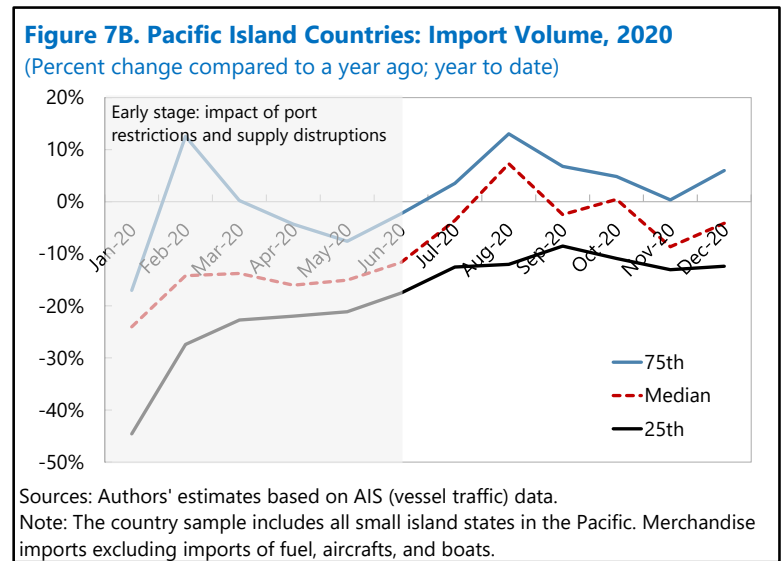

However, the supply impact appears to have been relatively short-lived, dissipating in the second half of 2020. In fact, for some Pacific islands, there was a full rebound in imports by the end of 2020, as discussed in the next subsection. This fits with the general findin gs of Cerdeiro and Komaromi (2020) that there were strong but short-lived supply spillovers of lockdowns through international trade.

\section{B. The Role of Tourism in the Later Stage}

After the initial stage, we see a differential evolution of imports between tourism-reliant Pacific islands and others. This is not surprising since tourism itself has a large import component (e.g., non-domestic goods consumed by tourists) and the fall in disposable income was severer in tourism-reliant islands, leading to a larger fall in domestic demand.

\footnotetext{
${ }^{15}$ Given the large transportation costs, Pa cific island have only a few la rge tra ding partners (Australia, China, Japan, New Zealand, United States), which make them vulnerable to supply shocks in those countries.

${ }^{16}$ Many organizations, including UNCTAD and other international bodies, issued recommendations and guidance underscoring the need for ships to meet international requirements, protecting port workers and sea farers from the pandemic, and for ports to remain open for shipping a nd intermodal transport operations.
} 
Indeed, for several Pacific islands, tourism accounts for a substantial share of GDP and employment, particularly for Fiji, Palau, Samoa, and Vanuatu (Figure 8). For these countries, tourism revenues essentially vanished after the first quarter of 2020 when countries closed their borders to international travel (Figure 9). In Fiji, Palau, Samoa, and Vanuatu, international tourism receipts fell by an estimated 17 to 29 percent of GDP in 2020 (Figure 10), with severe repercussions for economic activity in related industries, including accommodation, restaurants, retail, and real estate (Balasundharam and Koepke, 2021). ${ }^{17}$
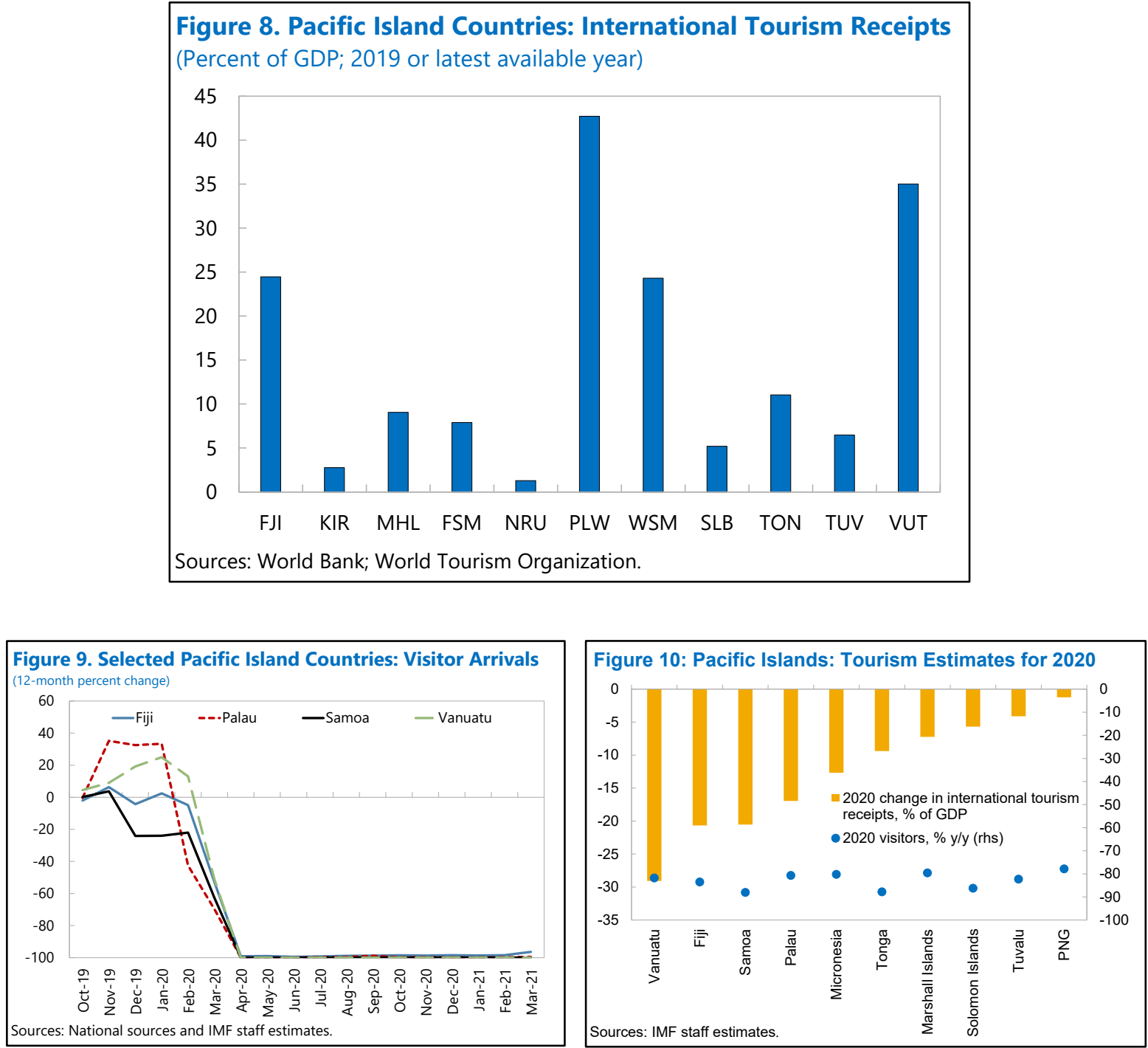

With the tourism industry collapsing due to the COVID-19 pandemic, imports dropped as much as 20 percent in some tourism-reliant countries. For the four Pacific islands that have published official trade value data for 2020, we see that those with higher reliance on tourism (Fiji and Samoa) experienced much larger declines in imports compared to others with lower or no dependence on tourism (Tonga and Tuvalu) (Figure 11). While similar official data on

\footnotetext{
${ }^{17}$ Remittances a re another im portant source of income for some Pa cific islands (Marshall Isla nds, Samoa, and Tonga ). However, a vailable data suggest remittances have held up rela tively well during the pandemic.
} 
trade volumes are not available, this differentiation in the rebound of trade activity is also apparent in our estimates of trade volume for these Pacific islands (Figures 12 and 14).
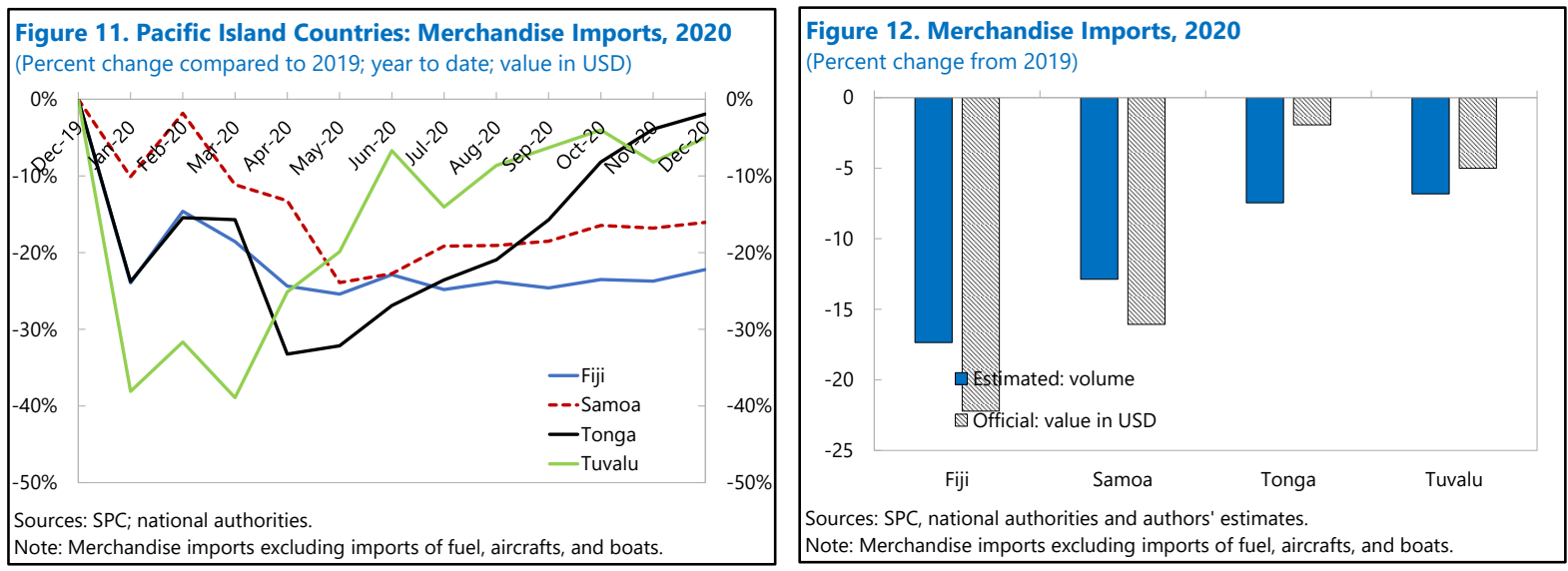

We also observe this differentiation for the Pacific islands that have yet to publish official trade data for 2020 (Figure 13). In particular, we find that in the early stage of the pandemic (first half of 2020), all small states in the Pacific saw import volumes decline substantially reflecting port closures and supply disruptions. However, in the later stage (second half of 2020), import volumes for Pacific islands with lower dependence on tourism rebounded, while they stayed low for those with higher dependence on tourism.

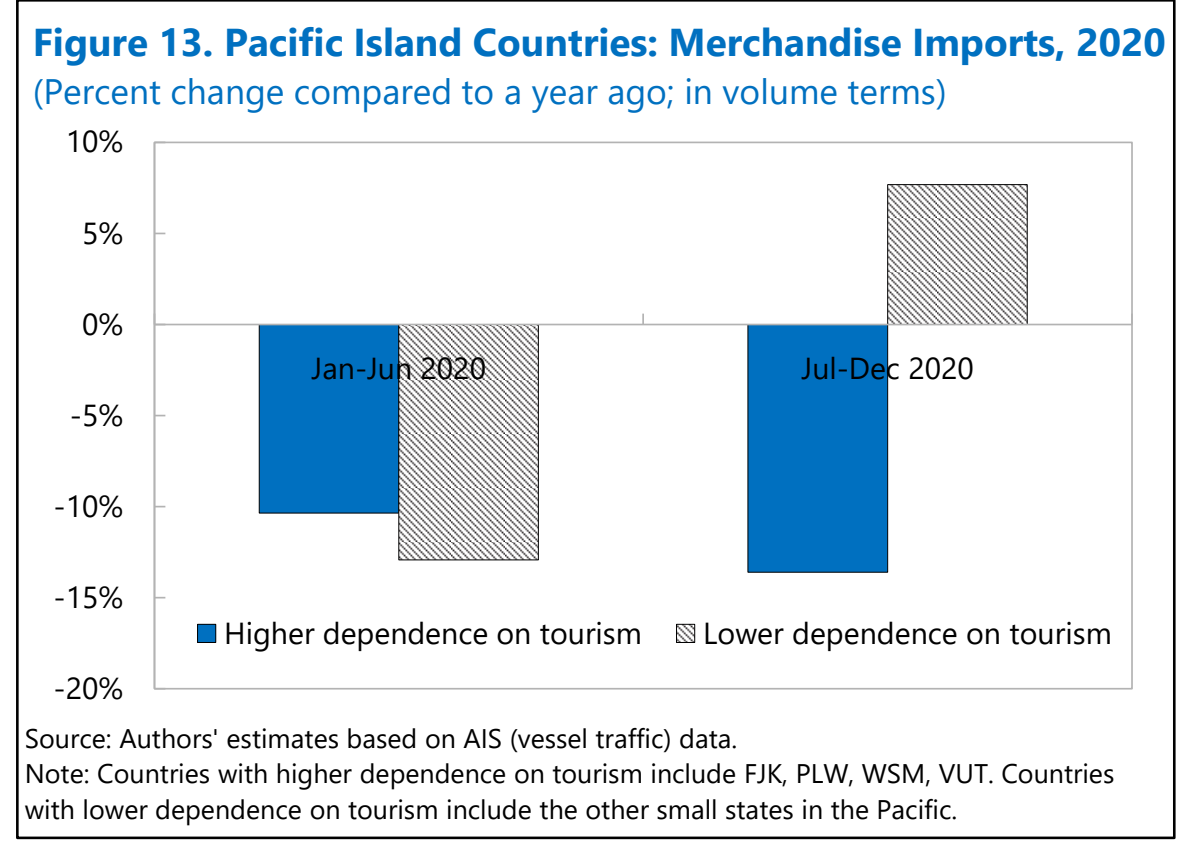

At the global level, the COVID-19 pandemic has weighed on economic activity through a negative shock on consumption (due to lockdowns, job losses, and declines in income), investment (due to heightened uncertainty), and exports (including tourism). Our estimates suggest that, for Pacific islands, the main impact may have come from the tourism channel. 
This is in line Furceri et al. (2021) who find that a robust determinant of initial output losses from the COVID-19 pandemic across countries was higher dependence on tourism. ${ }^{18}$ It is also in line with Milesi-Ferretti (2021), who further shows that the share of tourism activities in GDP was the single most important predictor of the growth shortfall in 2020 triggered by the COVID-19 crisis (even when compared to a variety of measures of the severity of the pandemic). Similarly, IMF (2021b) show that countries with a higher share of tourism revenues in GDP experienced a much sharper current account deterioration in 2020 (when compared to pre-pandemic forecasts), although the net effect of the tourism shock on the current account was partially offset by its induced compression of imports.

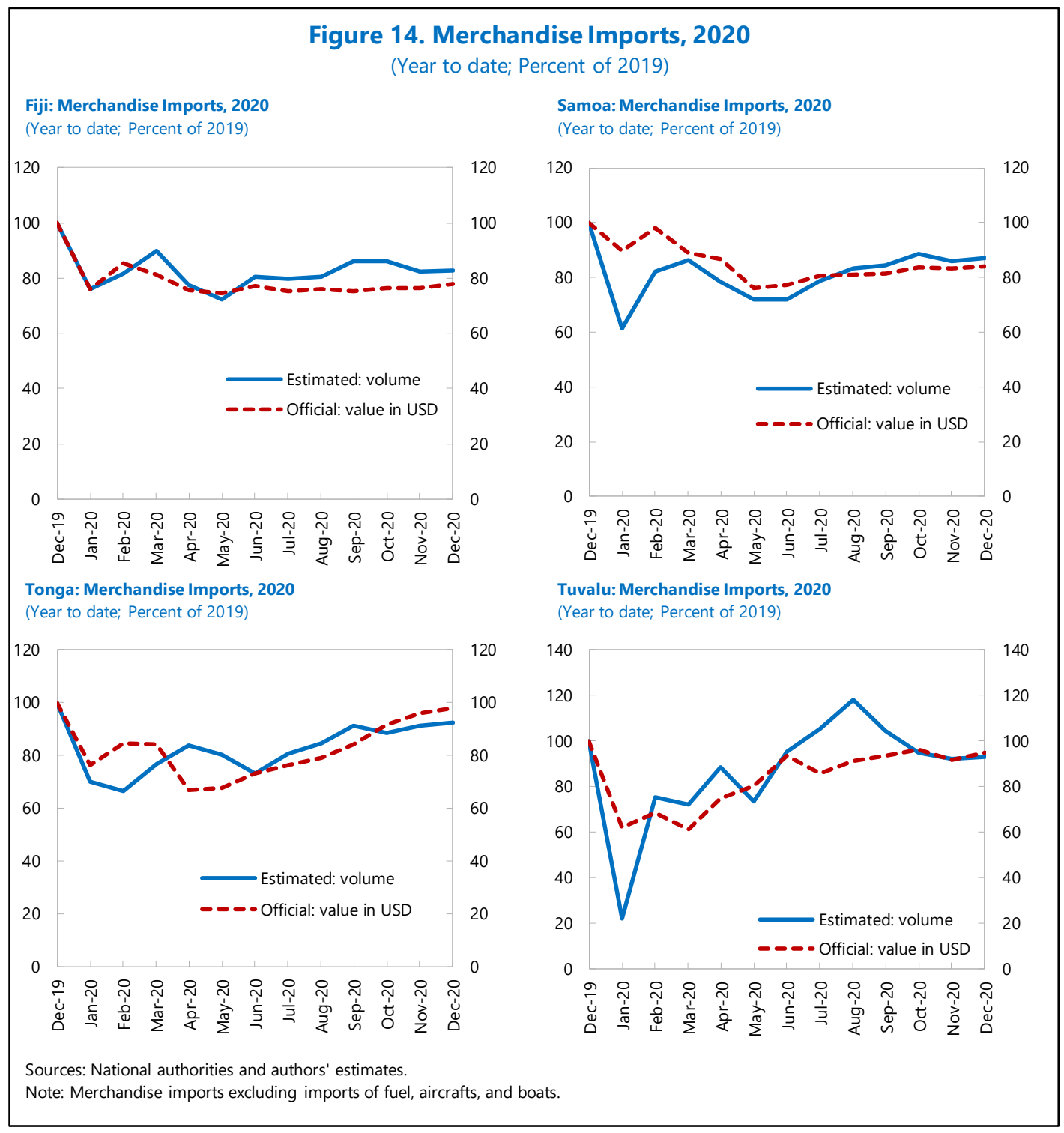

${ }^{18}$ The other factors are lower GDP per ca pita, more stringent containment measures, higher deaths per ca pita, more libera lized financial markets, higher pre-crisis growth, lower fiscal stimulus, higher ethnic and religious fractionalization, and more democratic regimes - factors rela tively less differentiated among Pa cific islands. 


\section{Conclusions And Possible Extensions}

In this paper, we constructed daily indicators of port and trade activity for Pacific islands based on satellite-based vessel tracking data from the UN Global Platform. We did so by developing an algorithm that employs several improvements to previous studies to track port and trade activity accurately at the country-level. Our work points to the importance of a deep understanding of the liner shipping industry that form the backbone of trade in the region to attain accurate results at the country-level. We provided an example of our approach by documenting the impact of COVID-19 pandemic on regional trade. Our results can be replicated by other national and international organizations with access to the UNGP.

We provided an example of our approach by documenting the impact of COVID-19 pandemic on regional trade. The COVID-19 pandemic has underscored the global interdependency of nations and set in motion new trends that may reshape global supply chains. It also brought to the fore the importance of maritime transport as an essential sector for the continued delivery of critical supplies and global trade in time of crisis.

Due to the almost real-time availability of data, the approach is particularly useful in times of natural disasters and other shocks due to climate change (i.e., when there is a high level of uncertainty and traditional indicators often become available only after a long delay). Hence, the approach can help monitor the impact of natural disasters and assist policymakers provide timely responses to such shocks. It could also help regional and international organizations provide timely advice to national authorities when they are hit with shocks. Finally, over the longer run, it could support regional capacity development efforts to fill data gaps.

As an application, we have focus on Pacific islands in this paper, but the methodology can be extended to various countries and adapted for specific purposes, such as:

- Small island states. The approach presented in this paper could be extended globally to other small island states, such as those in the Caribbean but also elsewhere as about a quarter of IMF's member countries are small states.

- Global supply chains. Aside from small states, we see potential to extend this work to economies active in the global supply chains through container shipping. In doing so, we believe it would be important (once again) to bring domain expertise (including on the operations of liner shipping companies) for accurate results at the country level.

- Tourism. With a few modifications, the approach could be extended to track tourism through cruise ships. With the anticipated pick-up in cruise activity after COVID-19, this could be a very helpful source of high-frequency indicator for countries that rely heavily on cruise tourism, such as those in the Caribbean. 
- Fishing license fees. With some modifications, the approach could also be extended to track fishing license fees that countries collect through vessel day schemes (VDS), a key source of fiscal revenue for countries in the Pacific. ${ }^{19}$

- Trade policy. The approach could be used to assess the impact of trade policies (e.g., changes in tariffs, trade sanctions, trade liberalizations) on trade patterns in real-time.

- Early indicator for economic activity. For countries that rely on maritime trade for key functions of the economy (either for imports or exports), this approach could serve as an early indicator of economic activity. In this context, the approach can be combined with other satellite data, such as night light from space (Hu and Yao, 2019).

Finally, apart from country-level analysis, our methodology can be extended to regional surveillance and network-level analysis. The networked environment implies that a shock to a port in the shipping network, such as a natural disaster, can affect shipping costs and trade flows for many countries in the network. This allows for forecasting trade shocks in the region (i.e., given the known transit times between ports), if any of the network components is disrupted (e.g., port disruption in a transshipment hub). Given the rigidity of the Pacific trade network, trade shocks would likely propagate without much adaptation (e.g., rerouting). Similarly, trade in the region could be monitored by tracking critical nodes in the regional shipping network. For instance, if port traffic is declining in Fiji-the transshipment hub for South Pacific - it may be an early indication of a similar trend for the rest of the region.

\footnotetext{
${ }^{19}$ Under a vessel day scheme (VDS), countries receive license fees from fishing vessels per day of fishing, not by fish catch. The VDS is the model used in the Pa cific under the Parties to the Nauru Agreement (PNA). Based on our a pproach, the number of days fishing vessels spend on sea can be used to track licensefees.
} 


\section{REFERENCES}

Achurra-Gonzalez, P.E., P. Angeloudis, N. Goldbeck, D. J. Graham, K. Zavitsas, and M. E. J. Stettler, 2019, "Evaluation of Port Disruption Impacts in the Global Liner Shipping Network. Journal of Shipping and Trade. 4 (3) https://doi.org/10.1186/s41072-019-0043-8

Adland, R., H. Jia and S. P. Strandenes, 2017, “Are AIS-based Trade Volume Estimates Reliable? The Case of Crude Oil Exports," Maritime Policy \& Management, 44:5, 657-665. http://dx.doi.org/10.1080/03088839.2017.1309470.

Arslanalp, S., M. Marini, and P. Tumbarello, 2019a, "Big Data on Vessel Traffic: Nowcasting Trade Flows in Real Time," IMF Working Paper No. 19/275 (Washington: International Monetary Fund).

— 2019b, "Reading the Sea Leaves: What Do Ship Movements Tell Us About International Trade-A Big Data Story," IMF Research Perspectives No. 21/2, December 2019.

Asian Development Bank (ADB), 2007, Oceanic Voyages: Shipping in the Pacific, Pacific Studies Series.

— 2017, Trade Facilitation for a More Inclusive and Connected Asia and Pacific Region: Progress and Way Forward, Manila.

—, 2019, Building Resilience in The Pacific: How ADB is Addressing Climate Change and Disaster Risks, Manila.

— 2020, Trade and Maritime Transport Trends in the Pacific, Manila.

Balasundharam, Vybhavi and Robin Koepke, 2021, "Diversion of Tourism Flows in the Asia \& Pacific Region: Lessons for COVID-19 Recovery.” IMF Working Paper, forthcoming.

Becker, A., A. Ng, D. McEvoy, J. Mullett, 2018, "Implications of Climate Change for Shipping: Ports and Supply Chains." Wiley Interdisciplinary Reviews: Climate Change: e508. https://doi.org/10.1002/wcc.508

Brancaccio G., M. Kalouptsidi, and T. Papageorgiou, 2020, "Geography, Transportation, and Endogenous Trade Costs," Econometrica, vol. 88(2), p. 657-691 https://doi.org/10.3982/ECTA15455

Briguglio L, 1995, "Small Island Developing States and their Economic Vulnerabilities," World Development 23:1615-1632. https://doi.org/10.1016/0305-750X(95)00065-K 
Cabezon, E., L. Hunter, P. Tumbarello, K. Washimi, and Y. Wu, 2015, "Enhancing Macroeconomic Resilience to Natural Disasters and Climate Change in the Small States of the Pacific," IMF Working Paper No. 15/125 (Washington: International Monetary Fund).

Cahoon S., S-L. Chen, B. Brooks, and G. Smith, 2016, "The Impact of Climate Change on Australian Ports and Supply Chains: The Emergence of Adaptation Strategies," in Climate Change Adaptation Planning for Ports, Routledge, ISBN 978-1-138-79790-1

Cerdeiro, D. A., A. Komaromi, 2020, "Supply Spillovers During the Pandemic: Evidence from High-Frequency Shipping Data," IMF Working Paper No. 20/284 (Washington: International Monetary Fund).

Cerdeiro, D. A., A. Komaromi, Y. Liu, and M. Saeed, 2020, "World Seaborne Trade in Real Time: A Proof of Concept for Building AIS-based Nowcasts From Scratch.” IMF Working Paper No. 20/57 (Washington: International Monetary Fund).

DHI, 2018, "DHI Vessel Hulls Catalogue: Data Sheets for Different Vessels in MIKE 21 Mooring Analysis," Technical report, DHI Group, Denmark.

Donaldson, D. and A. Storeygard, 2016, "The View from Above: Applications of Satellite Data in Economics," Journal of Economic Perspectives 30(4): 171-198.

Ducruet, C. and F. Zaidi, 2012, "Maritime Constellations: A Complex Network Approach to Shipping and Ports," Maritime Policy and Management 39(2), 151-168.

Furceri, D., M. Ganslmeier, J. D. Ostry, and N. Yang, 2021, "Initial Output Losses from the Covid-19 Pandemic: Robust Determinants" IMF Working Paper No. 21/18 (Washington: International Monetary Fund).

Ganapati S., W. F. Wong, O. Ziv, 2020, "Entrepôt: Hubs, Scale, and Trade Costs," CESifo Working Paper Series

Heiland, I., A. Moxnes, K. H. Ulltveit-Moe, and Y. Zi, 2019, "Trade from Space: Shipping Networks and the Global Implications of Local Shocks," CEPR Discussion Papers 14193, C.E.P.R. Discussion Papers.

Helble M., 2014, “The Pacific's Connectivity and Its Trade Implications,” ADBI Working Paper Series No: No. 499, September 2014

Hensel, T., C. Uge, C. Jahn, 2020, “Green Shipping: Using AIS Data to Assess Global Emissions," Sustainability Management Forum 28,39-47 https://doi.org/10.1007/s00550-020-00498-x 
Hoffmann Pham, K., J. Boy, M. Luengo-Oroz, 2018, "Data Fusion to Describe and Quantify Search and Rescue Operations in the Mediterranean Sea," IEEE 5th International Conference on Data Science and Advanced Analytics, 514-523.

Hu, Y. and J. Yao, 2019, “Illuminating Economic Growth,” IMF Working Paper No. 19/77 (Washington: International Monetary Fund).

International Monetary Fund, 2017, "Big Data: Potential, Challenges and Statistical Implications," Staff Discussion Note prepared by C. Hammer, D. Kostroch, and G. Quirós-Romero, Washington, DC.

_ 2018, "Overarching Strategy on Data and Statistics at the Fund in the Digital Age," IMF Policy Paper, Washington, DC.

— 2019, "Fiscal Policies for Paris Climate Strategies—From Principle to Practice," IMF Policy Paper, Washington, DC.

—_, 2021a, "Fiscal Policies to Address Climate Change in Asia and the Pacific" IMF Departmental Paper No. 21/07, Washington, DC.

— 2021b, External Sector Report: Divergent Recoveries and Global Imbalances, Washington, DC, August.

J. P. Morgan, 2020, "Rocking the Boat with Alternative Data: Introducing the JPM BIDSI Trade Tracker," Economic Research Special Report prepared by Anthony Wong, February 20, 2020.

Jia, H., V. Prakash, and T. Smith, 2019. "Estimating Vessel Payloads in Bulk Shipping using AIS Data," International Journal of Shipping and Transport Logistics 11(1), 25-40

Lam, JSL., C. Liu, X. Gou. 2017, “Cyclone Risk Mapping for Critical Coastal Infrastructure: Cases of East Asian Seaports." Ocean and Coastal Management 141:43-54.

Lam, JSL., S. Su, 2015, "Disruption Risks and Mitigation Strategies: An Analysis of Asian Ports" Maritime Policy \& Management, 42:5, 415-435

Milesi-Ferretti, Gian Maria, 2021, “The Travel Shock,” Brookings Institution, Washington, DC.

Noyvirt A., 2019, “Faster Indicators of UK Economic Activity: Shipping," Office for National Statistics (ONS). https://datasciencecampus.ons.gov.uk/projects/fasterindicators-of-uk-economic-activity-shipping/

Oceanbolt, 2020, "Real-Time Data on Seaborne Dry Bulk Commodities: Estimating Bauxite Export Flows from Ghana," November 2020 
OECD, 2020, Revenue Statistics in Asian and Pacific Economies 2020, OECD Publishing, Paris, https://doi.org/10.1787/d47d0ae3-en

Parry, I., D. Heine, K. Kizzier, and T. Smith, 2018, “Carbon Taxation for International Maritime Fuels: Assessing the Options," IMF Working Paper 18/203 (Washington: International Monetary Fund).

Riku T., R. Shibasaki, and H. Kato, 2021, "Pacific Islands: Small and Dispersed Sea-Locked Islands" in Global Logistics Network Modelling and Policy. https://doi.org/10.1016/B978-0-12-814060-4.00014-9

Silver, M., 2010, "The Wrongs and Rights of Unit Value Indices," Review of Income and Wealth, Volume 56, Issue 1.

Stamer, V., 2021, "Thinking Outside the Container: A Machine Learning Approach to Forecasting Trade Flows," Kiel Working Paper No. 2179, January 2021

United Nations, 2021, Report of the Global Working Group on Big Data for Official Statistics, Statistical Commission, Fifty-Second session, March 2021

United Nations Conference on Trade and Development (UNCTAD), 2014, Review of Maritime Transport, Special Chapter on Small Island Developing States (SIDS), November 2014

— 2018, Review of Maritime Transport, November 2018

— 2020, Review of Maritime Transport, November 2020

Verschuur J., E. E. Koks, J. W. Hall, 2020, “Port Disruptions due to Natural Disasters: Insights into Port and Logistics Resilience" Transportation Research D. 85, 102393 https://doi.org/10.1016/j.trd.2020.102393

__ 2021a, "Global Economic Impacts of COVID-19 Lockdown Measures Stand Out in High-frequency Shipping Data" PLoS ONE 16(4): e0248818. https://doi.org/10.1371/journal.pone.0248818

— 2021 b, "Ports' Criticality in International Trade and Global Supply-Chains" mimeo.

Verschuur J., E. E. Koks, S. Li, and J.W. Hall, 2021, “A Global Multi-Hazard Risk Analysis of Port Infrastructure" forthcoming.

Vespe M., M. Gibin, A. Alessandrini, F. Natale, F. Mazzarella, and G. C. Osio, 2016, "Mapping EU Fishing Activities Using Ship Tracking Data," Journal of Maps, 12:sup1, 520-525, https://doi.org/10.1080/17445647.2016.1195299 
Annex Table I. Central Location Of PaCific Island Ports

\begin{tabular}{|c|c|c|c|}
\hline Country & Port & Latitude / Longitude & Source \\
\hline Fiji & Suva & $18^{\circ} 08^{\prime} 00.8^{\prime \prime S} 178^{\circ} 25^{\prime} 26.6^{\prime \prime E}$ & WPI/Google Maps \\
\hline Fiji & \begin{tabular}{|l|} 
Lautoka \\
\end{tabular} & $17^{\circ} 36^{\prime} 16.3^{\prime \prime S} 177^{\circ} 26^{\prime} 18.4^{\prime \prime E}$ & WPI/Google Maps \\
\hline Fiji & Savusavu & $16^{\circ} 46^{\prime} 41.1^{\prime \prime} \mathrm{S} 179^{\circ} 19^{\prime} 31.6^{\prime \prime} \mathrm{E}$ & WPI/Google Maps \\
\hline Fiji & Malau 1/ & $16^{\circ} 21^{\prime} 34.9^{\prime \prime} \mathrm{S} 179^{\circ} 21^{\prime} 57.5^{\prime \prime} \mathrm{E}$ & WPI/Google Maps \\
\hline Fiji & Nabouwalu/Wairiki 1/ & $16^{\circ} 59^{\prime} 37.0^{\prime \prime S} 178^{\circ} 41^{\prime} 08.5^{\prime \prime E}$ & AIS/Google Maps \\
\hline Kiribati & Betio/Tarawa & $1^{\circ} 22^{\prime} 01.9^{\prime \prime} \mathrm{N} 172^{\circ} 56^{\prime} 07.7^{\prime \prime} \mathrm{E}$ & WPI/Google Maps \\
\hline Kiribati & Kiritimati & $2^{\circ} 00^{\prime} 24.2^{\prime \prime} \mathrm{N} 157^{\circ} 29^{\prime} 16.4^{\prime \prime} \mathrm{W}$ & AIS/Google Maps \\
\hline Marshall Islands & Majuro & 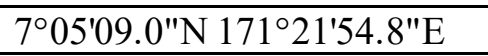 & WPI/Google Maps \\
\hline Marshall Islands & \begin{tabular}{|l|} 
Ebeye $2 /$ \\
\end{tabular} & $8^{\circ} 46^{\prime} 44.2^{\prime \prime} \mathrm{N} 167^{\circ} 44^{\prime} 08.8^{\prime \prime} \mathrm{E}$ & WPI/Google Maps \\
\hline FSM & Yap & $9^{\circ} 30^{\prime} 56.5^{\prime \prime} \mathrm{N} 138^{\circ} 07^{\prime} 31.4^{\prime \prime} \mathrm{E}$ & WPI/Google Maps \\
\hline FSM & Chuuk & $7^{\circ} 26^{\prime} 44.5^{\prime \prime} \mathrm{N} 151^{\circ} 50^{\prime} 23.0^{\prime \prime} \mathrm{E}$ & WPI/Google Maps \\
\hline FSM & Pohnpei & $6^{\circ} 58^{\prime} 46.6^{\prime \prime} \mathrm{N} 158^{\circ} 12^{\prime} 03.9^{\prime \prime} \mathrm{E}$ & WPI/Google Maps \\
\hline FSM & Kosrae & $5^{\circ} 21^{\prime} 01.7^{\prime \prime} \mathrm{N} 162^{\circ} 57^{\prime} 24.0^{\prime \prime} \mathrm{E}$ & WPI/Google Maps \\
\hline Nauru & Nauru & $0^{\circ} 31^{\prime} 46.9^{\prime \prime} \mathrm{S} 166^{\circ} 54^{\prime} 26.9^{\prime \prime} \mathrm{E}$ & WPI/Google Maps \\
\hline Palau & \begin{tabular}{|l|} 
Malakal \\
\end{tabular} & $7^{\circ} 19^{\prime} 51.1^{\prime \prime} \mathrm{N} 134^{\circ} 27^{\prime} 25.2^{\prime \prime} \mathrm{E}$ & WPI/Google Maps \\
\hline Samoa & Apia & $13^{\circ} 49^{\prime} 34.9^{\prime \prime} \mathrm{S} 171^{\circ} 45^{\prime} 41.8^{\prime \prime} \mathrm{W}$ & WPI/Google Maps \\
\hline Solomon Islands & Honiara & $\begin{array}{l}9^{\circ} 25^{\prime} 36.8^{\prime \prime} \mathrm{S} 159^{\circ} 57^{\prime} 36.0^{\prime \prime} \mathrm{E} \\
9^{\circ} 24^{\prime} 45.6^{\prime \prime} \mathrm{S} 160^{\circ} 01^{\prime} 06.2^{\prime \prime} \mathrm{E}\end{array}$ & WPI/Google Maps \\
\hline Solomon Islands & \begin{tabular}{|l|} 
Noro \\
\end{tabular} & $8^{\circ} 14^{\prime} 07.4^{\prime \prime S} 157^{\circ} 11^{\prime} 47.6^{\prime \prime E}$ & WPI/Google Maps \\
\hline Solomon Islands & \begin{tabular}{|l|} 
Mbulo \\
\end{tabular} & $9^{\circ} 35^{\prime} 24.0^{\prime \prime} \mathrm{S} 160^{\circ} 37^{\prime} 01.2^{\prime \prime} \mathrm{E}$ & AIS/Google Maps \\
\hline Solomon Islands & Ndora $1 /$ & $8^{\circ} 23{ }^{\prime} 27.6^{\prime \prime S} 157^{\circ} 33^{\prime} 14.4^{\prime \prime E}$ & AIS/Google Maps \\
\hline Solomon Islands & \begin{tabular}{|l|} 
Seghe 1/ \\
\end{tabular} & $8^{\circ} 34^{\prime} 59.8^{\prime \prime} \mathrm{S} 157^{\circ} 56^{\prime} 01.6^{\prime \prime} \mathrm{E}$ & AIS/Google Maps \\
\hline Solomon Islands & Gizo 1/ & $8^{\circ} 5^{\prime} 60.0^{\prime \prime S} 156^{\circ} 50^{\prime} 60.0^{\prime \prime} \mathrm{E}$ & WPI/Google Maps \\
\hline Solomon Islands & Ringgi 1/ & $8^{\circ} 7^{\prime} 00.0^{\prime \prime S} 157^{\circ} 06^{\prime} 00.0^{\prime \prime} \mathrm{E}$ & WPI/Google Maps \\
\hline Solomon Islands & \begin{tabular}{|l|} 
Rennell Island 1/ \\
\end{tabular} & $11^{\circ} 41^{\prime} 06.0^{\prime \prime S} 160^{\circ} 18^{\prime} 06.5^{\prime \prime E}$ & AIS/Google Maps \\
\hline Solomon Islands & \begin{tabular}{|l|} 
Lughughi 1/ \\
\end{tabular} & $11^{\circ} 37^{\prime} 42.6^{\prime \prime S} 160^{\circ} 05^{\prime} 16.8^{\prime \prime} \mathrm{E}$ & AIS/Google Maps \\
\hline Tonga & Nuku'alofa & $21^{\circ} 08^{\prime} 13.6^{\prime \prime S} 175^{\circ} 11^{\prime} 10.4^{\prime \prime} \mathrm{W}$ & WPI/Google Maps \\
\hline Tonga & Neiafu & $18^{\circ} 39^{\prime} 07.3^{\prime \prime S} 173^{\circ} 59^{\prime} 06.6^{\prime \prime} \mathrm{W}$ & WPI/Google Maps \\
\hline Tuvalu & \begin{tabular}{|l|} 
Funafuti \\
\end{tabular} & $8^{\circ} 30^{\prime} 10.9^{\prime \prime} \mathrm{S} 179^{\circ} 11^{\prime} 44.0^{\prime \prime E}$ & WPI/Google Maps \\
\hline Vanuatu & \begin{tabular}{|l|} 
Port Vila \\
\end{tabular} & $17^{\circ} 45^{\prime} 22.0^{\prime \prime S} 168^{\circ} 18^{\prime} 07.4^{\prime \prime E}$ & WPI/Google Maps \\
\hline Vanuatu & Santo/Luganville & $15^{\circ} 30^{\prime} 55.1^{\prime \prime S ~} 167^{\circ} 11^{\prime} 18.3^{\prime \prime E}$ & WPI/Google Maps \\
\hline
\end{tabular}

Note: WPI=World Port Index.

1/ Specia lized ports for exporting specific commodities (e.g., cane sugar, timber).

2 / Ebeye is identified separately from theKwajalein port that services the U.S. army base in the a toll. 
Annex Charts I. PaCific Island Countries: Port Calls, JANUARY 2019-FEBRUARY 2021

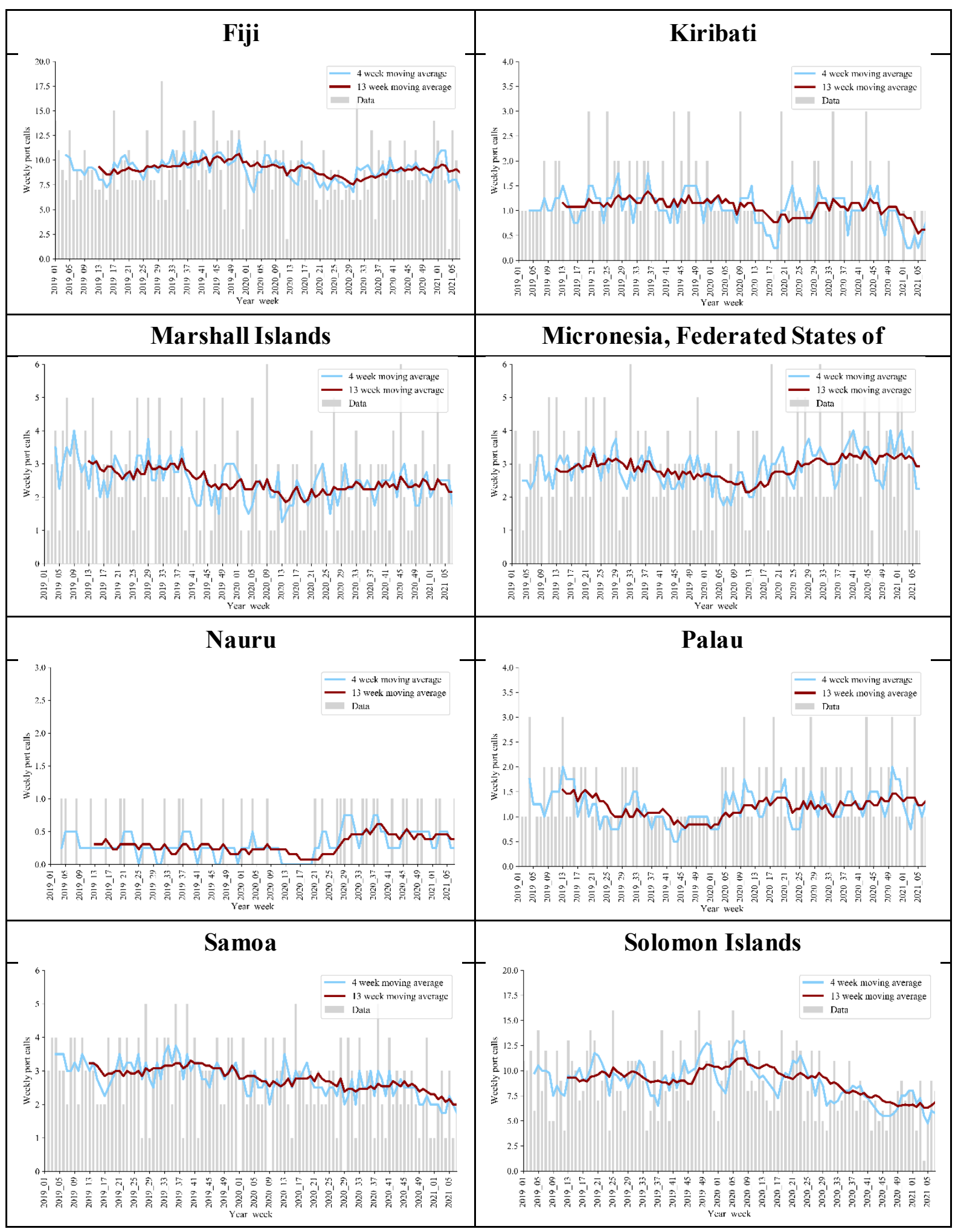

CInternational Monetary Fund. Not for Redistribution 


\section{Annex Charts I. PaCific Island Countries: Port Calls, JANUARY 2019-FEBRUARY 2021 (CONTINUED)}

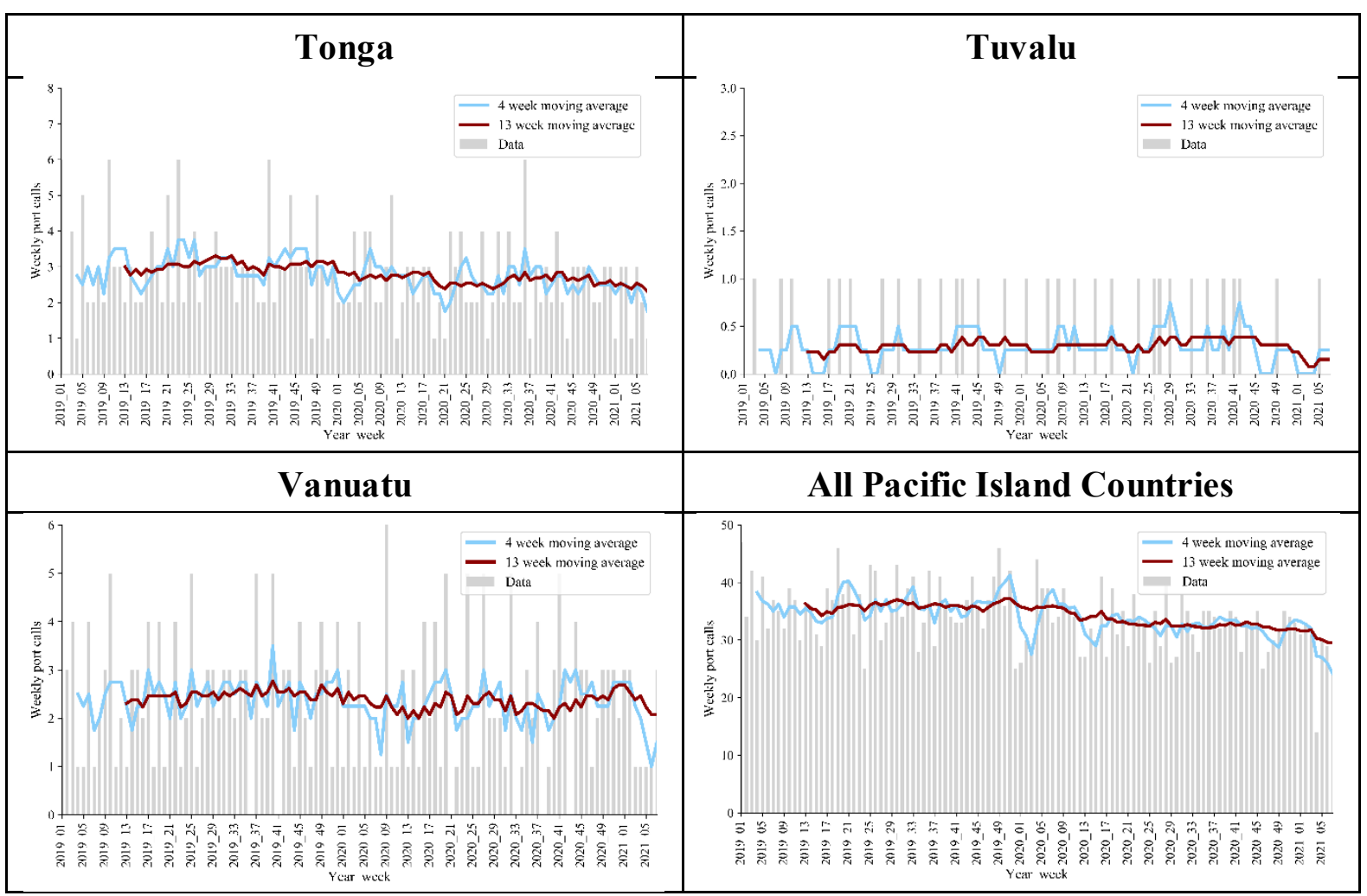


ANNEX ChARTS II. PACIFIC ISLAND COUNTRIES: IMPORT VOLUME, J ANUARY 2019-FEBRUARY 2021

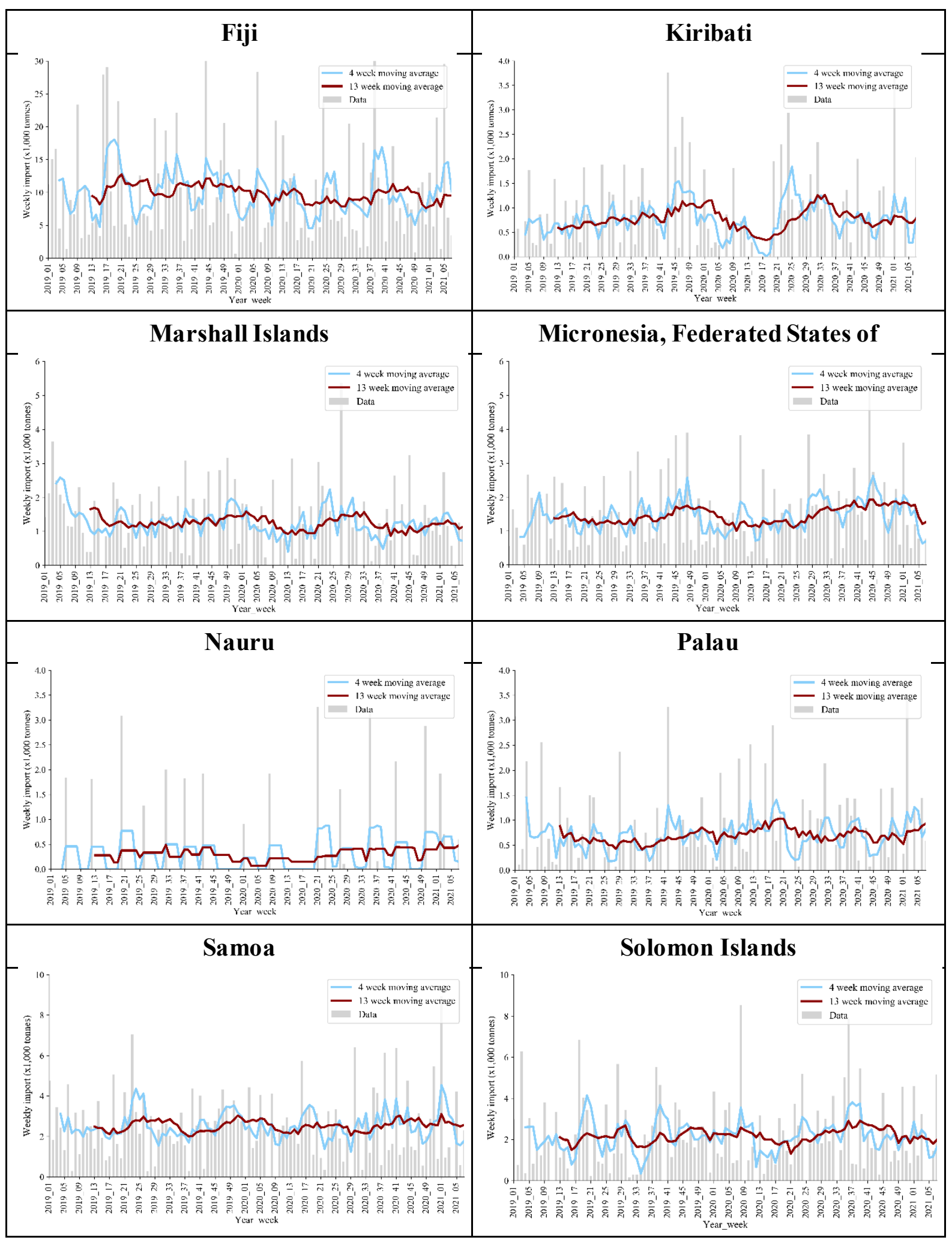




\section{ANNEX ChaRTS II. PACIFIC ISLAND COUNTRIES: IMPORT VOLUMe, JANUARY 2019-FEBRUARY 2021 (CONTINUED)}

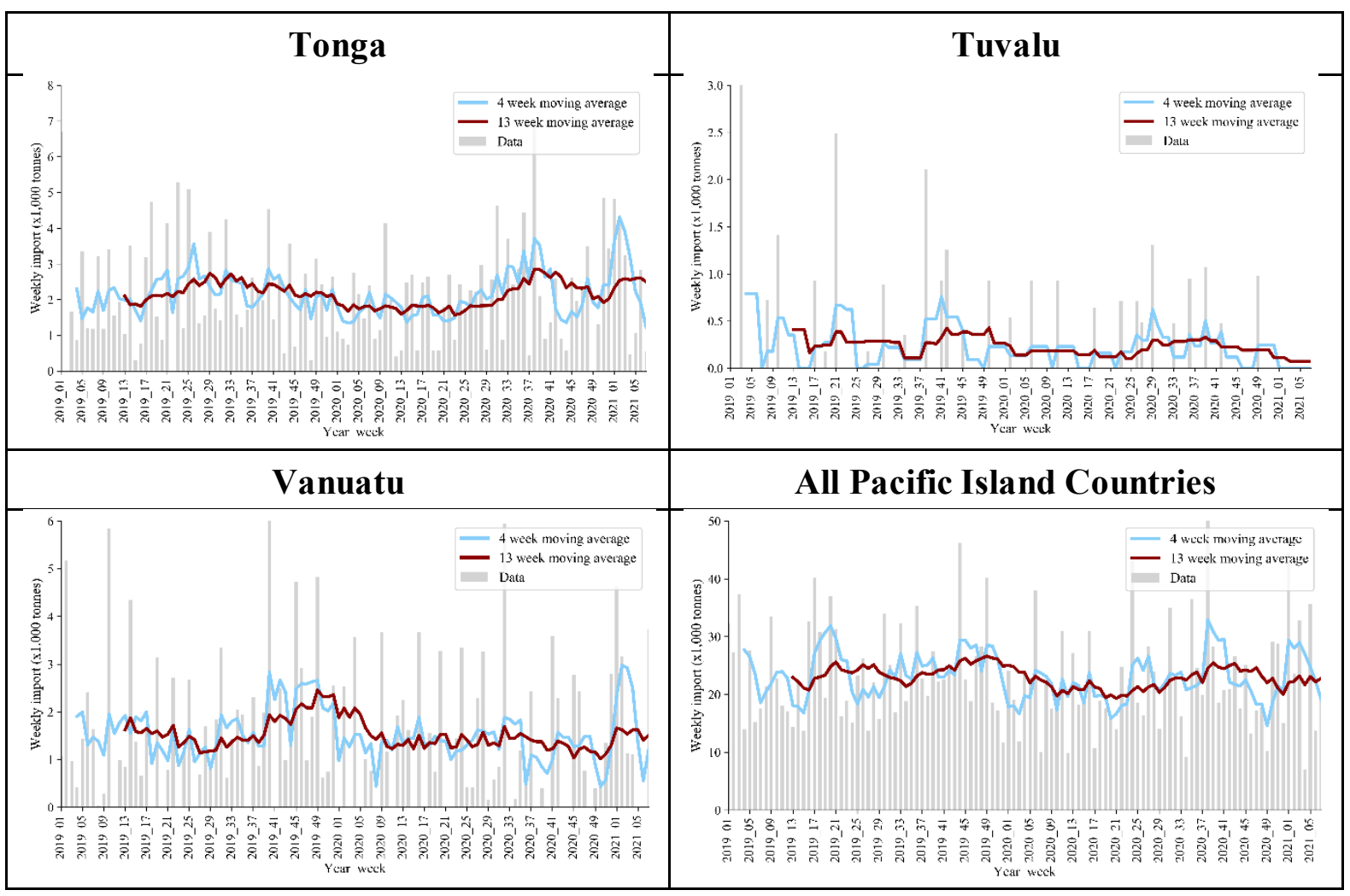

